\title{
The coupled chemistry-climate model LMDz-REPROBUS: description and evaluation of a transient simulation of the period 1980-1999
}

\author{
L. Jourdain ${ }^{1, *}$, S. Bekki ${ }^{1}$, F. Lott $^{2}$, and F. Lefèvre ${ }^{1}$ \\ ${ }^{1}$ Service d'Aéronomie, Université Paris 6, CNRS, 4 place jussieu, 75005 Paris, France \\ ${ }^{2}$ Laboratoire de Météorologie Dynamique, Université Paris 6, CNRS, 4 place jussieu, 75005 Paris, France \\ *now at: the Jet Propulsion Laboratory, 4800 Oak Grove Dr., 91109 Pasadena, CA, USA
}

Received: 4 July 2007 - Revised: 31 March 2008 - Accepted: 21 April 2008 - Published: 11 June 2008

\begin{abstract}
We present a description and evaluation of the Chemistry-Climate Model (CCM) LMDz-REPROBUS, which couples interactively the extended version of the Laboratoire de Météorologie Dynamique General Circulation Model (LMDz GCM) and the stratospheric chemistry module of the REactive Processes Ruling the Ozone BUdget in the Stratosphere (REPROBUS) model. The transient simulation evaluated here covers the period 1980-1999. The introduction of an interactive stratospheric chemistry module improves the model dynamical climatology, with a substantial reduction of the temperature biases in the lower tropical stratosphere. However, at high latitudes in the Southern Hemisphere, a negative temperature bias, that is already present in the GCM version, albeit with a smaller magnitude, leads to an overestimation of the ozone depletion and its vertical extent in the CCM. This in turn contributes to maintain low polar temperatures in the vortex, delay the break-up of the vortex and the recovery of polar ozone. The latitudinal and vertical variation of the mean age of air compares favourable with estimates derived from long-lived species measurements, though the model mean age of air is $1-3$ years too young in the middle stratosphere. The model also reproduces the observed "tape recorder" in tropical total hydrogen $\left(=\mathrm{H}_{2} \mathrm{O}+2 \times \mathrm{CH}_{4}\right)$, but its propagation is about $30 \%$ too fast and its signal fades away slightly too quickly. The analysis of the global distributions of $\mathrm{CH}_{4}$ and $\mathrm{N}_{2} \mathrm{O}$ suggests that the subtropical transport barriers are correctly represented in the simulation. LMDz-REPROBUS also reproduces fairly well most of the spatial and seasonal variations of the stratospheric chemical species, in particular ozone. However, because of the Antarctic cold bias, large discrepancies are found for most species at high latitudes in the South-
\end{abstract}

Correspondence to: L. Jourdain

(ljourd@gmail.com) ern Hemisphere during the spring and early summer. In the Northern Hemisphere, polar ozone depletion and its variability are underestimated in the simulation.

Keywords. Atmospheric composition and structure (Middle atmosphere - composition and chemistry) - Meteorology and atmospheric dynamics (Middle atmosphere dynamics)

\section{Introduction}

Climate change and stratospheric ozone are coupled issues (World Meteorological Organisation/United Nations Environment Program (WMO/UNEP), 2007). Climate changes affect the dynamical structure and the chemical composition of the stratosphere in various ways through changes in the tropospheric wave forcing and through in situ changes in the radiative and chemical processes. In return, the stratosphere might play a more significant and complex role in tropospheric dynamics and climate than previously thought. Recent studies have indicated that stratospheric dynamical perturbations, caused by internal variability or in-situ radiative forcings, may significantly influence the troposphere. In particular, strong correlation between the strength of the stratospheric polar vortex and the Arctic Oscillation, the dominant pattern of surface weather variability in the extratropics of the Northern Hemisphere, has been found in meteorological analyses with an apparent downward propagation of stratospheric circulation anomalies to the troposphere (Baldwin and Dunkerton, 2001). Since ozone strongly interacts with the solar and terrestrial radiation, stratospheric ozone perturbations can directly influence tropospheric dynamics through changes to the radiative balance of the atmosphere (IPCC, 2001). In particular, recent studies have shown that stratospheric ozone depletion in the Southern

Published by Copernicus Publications on behalf of the European Geosciences Union. 
Hemisphere has contributed to increase the strength of the midlatitudes tropospheric winds and decrease the temperature over the Antarctic continent through both a direct radiative forcing and a dynamical coupling (WMO, 2007). Furthermore, stratospheric ozone also exerts a major influence on the chemical composition of the troposphere through chemically-driven mechanisms. For example, the flux of ozone coming from the stratosphere represents a major term in the tropospheric ozone budget (Karlsldottir et al., 2000; IPCC, 2001) and stratospheric ozone levels are a determining factor in the amount of UV radiation reaching the troposphere and driving its chemistry (Madronich and Granier, 1992). As a result, stratospheric ozone perturbations can affect the oxidation efficiency of the troposphere and hence the levels of greenhouse gases such as tropospheric ozone and methane (Bekki et al., 1994). Finally, this influence of the stratosphere onto the troposphere has implications for understanding external climate forcing agents, such as the solar variability or volcanic eruptions that perturb directly the dynamics and chemistry of the stratosphere. Indeed, as discussed above, stratospheric perturbations may propagate to the troposphere through a mix of radiative, chemical and dynamical mechanisms. Quantifying the impact of theses natural forcings on the climate with respect to anthropogenic forcings is an important issue in climate change assessments.

The study of the interactions between climate change and stratospheric ozone requires the use of Chemistry-Climate Models (CCMs) (Austin et al., 2003; Eyring et al., 2006). A CCM is usually composed of a General Circulation Model (GCM) coupled to a chemistry module. The modelcalculated concentrations of radiatively species are used as input in the radiation code, allowing the chemical, radiative and dynamics processes to fully interact.

The purpose of this paper is to present the reference evaluation of the stratospheric CCM LMDz-REPROBUS that is part of the IPSL Earth system model. The atmospheric component of the Earth System model has been extended vertically to cover the domain of the stratosphere (Lott et al., 2005) and then coupled interactively with a stratospheric chemistry module. The simulated stratosphere of this coupled model is compared against a range of observations in order to evaluate the qualities and deficiencies of the model. This overall thorough evaluation is a necessary step before using the model for specific sensitivity studies or coupling to the rest of the Earth system model. Note that this model has also been intercompared with other CCMs in the framework of Eyring et al. (2006).

The plan of the paper is as follows. Section 2 presents the model and the experimental set-up. In Sect. 3, the climatological performances of the model regarding dynamics, transport and chemistry are evaluated from comparisons with meteorological analysis and observations. The results are summarized and discussed in Sect. 4.

\section{Model description and simulations}

The dynamical model used is the extended version of the $\mathrm{LMDz}$ fourth-generation atmospheric GCM described in Lott et al. (2005). Its performances in the stratosphere and with a fixed ozone climatology are described in this paper, where a particular emphasis given to the simulation of the midlatitudes variability. An evaluation of its tropospheric climatology can also be found in Lott (1999) for the midlatitudes, and in $\mathrm{Li}$ (1999) for the tropics. Its tropospheric version is largely used in the French Research community (Hourdin et al., 2005; Bony et al., 2004; Quaas et al., 2004; Reddy and Boucher, 2004, among others) and starts to include interactive tropospheric chemistry (Hauglustaine et al., 2004). This model is also the atmospheric component of the IPSL Earth System model (Dufresne et al., 2002).

LMDz is a grid point model. In the horizontal direction, the equations are discretized on a staggered latitudelongitude Arakawa-C grid. It currently uses a uniform resolution of $2.5^{\circ}$ in latitude and $3.75^{\circ}$ in longitude. In the vertical direction, the model uses hybrid sigma pressure coordinates with 50 levels extending from the surface to $0.07 \mathrm{hPa}$ $(\sim 65 \mathrm{~km})$. The resolution in the stratosphere varies slowly from $1 \mathrm{~km}$ at $z=12 \mathrm{~km}$ to $3 \mathrm{~km}$ at $z=50 \mathrm{~km}$ and reaches $6 \mathrm{~km}$ at the model top.

The salient features of the physical parameterizations used in the model are: a radiation scheme based on the ECMWF scheme (Morcrette, 1989), a convection scheme based on Tiedtke (1989), a Subgrid Scale Orography (which forces orographic gravity waves) scheme based on Lott and Miller (1997) and Lott (1999), and a Doppler-spread nonorographic gravity waves scheme based on Hines (1997a, b) and adapted from Manzini et al. (1997). Note that compared to the stratospheric version in Lott et al. (2005), the parameter $\beta$ of the Subgrid Scale Orography scheme that controls the amount of mountain gravity waves that propagate toward the middle atmosphere have been slightly modified. It is now equal to $\beta=0.8$ (instead of $\beta=0.9$ ): there are twice as many mountain gravity waves reaching the stratosphere. This change was needed for our model to have a warmer Stratospheric North Pole in winter. Otherwise, the slightly too cold North Pole Temperature found in Lott et al. (2005) (see their Fig. 10) induces far too much PSC and ozone destruction by heterogeneous chemistry. Note also that the stratospheric version of LMDz also includes a Rayleigh drag sponge layer between $55 \mathrm{~km}$ and $65 \mathrm{~km}$ that damps the resolved waves and not the mean-flow (Shepherd et al., 1996).

The transport of tracers is calculated using the Van Leer scheme I (a first-order volume finite scheme with slope limitation) (Van Leer, 1977; Hourdin and Armengaud, 1999).

The chemistry model is the chemistry module of the REPROBUS chemistry-transport model (Lefèvre et al., 1994, 1998). The chemistry model contains a detailed description of $\mathrm{O}_{\mathrm{x}}, \mathrm{NO}_{\mathrm{x}}, \mathrm{HO}_{\mathrm{x}}, \mathrm{ClO}_{\mathrm{x}}, \mathrm{BrO}_{\mathrm{x}}$ and $\mathrm{CHO}_{\mathrm{x}}$ chemistry. It calculates the chemical evolution of 55 species using 
160 gas-phase reactions and 6 heterogeneous reactions on sulphuric acid aerosols and PSCs. Reaction rates coefficients are taken from the recommendations of Sander et al. (2003). The photolysis rates are calculated at every time step using a look-up table from the Tropospheric and Ultraviolet visible (TUV) model (Madronich and Flocke, 1998) tabulated for 81 altitudes, 7 total ozone columns and 27 solar zenith angles. In the model, heterogeneous reactions take place on liquid binary $\left(\mathrm{H}_{2} \mathrm{O} / \mathrm{H}_{2} \mathrm{SO}_{4}\right)$ and ternary $\left(\mathrm{H}_{2} \mathrm{O} / \mathrm{H}_{2} \mathrm{SO}_{4} / \mathrm{HNO}_{3}\right)$ aerosols as well as on solid NAT or ice particles. The aerosol scheme (Carslaw et al., 1995) that simulates the surface and the composition of liquid aerosols assumes instantaneous thermodynamic equilibrium between the aerosol phase and the gas-phase (no kinetic barrier to condensation/evaporation and phase transition). Therefore, for example, ice particles form on NAT particles once the ice point is reached. The irreversible vertical transfer of $\mathrm{HNO}_{3}$ and $\mathrm{H}_{2} \mathrm{O}$ due to the sedimentation of PSCs (i.e. denitrification) is also taken into account.

In this study, we have performed a transient simulation of the period 1975-2000 using the CCM. The dynamical tendencies are evaluated every $3 \mathrm{~min}$, the tracers advection and the chemical tendencies are evaluated every $15 \mathrm{~min}$, the physical processes are evaluated every $30 \mathrm{~min}$, except for the radiation transfer calculations that evaluated every $2 \mathrm{~h}$ only. In order to save computing time, the model chemistry is only integrated above the level $13(\sim 400 \mathrm{hPa})$. Below this level, the chemical composition of the CCM is forced with a transient simulation from a global 2-D model.

The 2-D model is a global 2-D chemistry-transport-aerosol model extending from the ground to $60 \mathrm{~km}$ that is fully interactive in the stratosphere (Bekki and Pyle, 1992; Jones et al., 1995)). The model contains a detailed description of $\mathrm{O}_{\mathrm{x}}, \mathrm{NO}_{\mathrm{x}}, \mathrm{HO}_{\mathrm{x}}, \mathrm{ClO}_{\mathrm{x}}, \mathrm{BrO}_{\mathrm{x}}, \mathrm{CHO}_{\mathrm{x}}$, and $\mathrm{SO}_{\mathrm{x}}$ photochemistry that is very similar to the CCM description. It uses recommended photochemical data (Sanders et al., 2003). It also includes a full microphysical aerosol scheme that allows to simulate the impact of volcanic eruptions on the stratospheric aerosol layer (Bekki and Pyle, 1994). The 2-D model is integrated from 1958 to 2000 with the temporal evolution of the mixing ratios of source gases $\left(\mathrm{CO}_{2}, \mathrm{CH}_{4}, \mathrm{~N}_{2} \mathrm{O} \mathrm{CFC} 11\right.$, CFC12, minor CFCs, HFCs, $\mathrm{CH}_{3} \mathrm{Cl}, \mathrm{CH}_{3} \mathrm{Br}$, Halons) prescribed at the surface on a monthly basis according to a standard WMO scenario (WMO, 1998). The effects of the volcanic eruptions of Agung in 1963, El Chichon in 1983 and Mount Pinatubo in 1991 are simulated by injecting 7, 10 and $20 \mathrm{MT}$ of $\mathrm{SO}_{2}$ in the tropics.

The forcing of the CCM chemical composition with the 2-D fields below $400 \mathrm{hPa}$ acts as a sink in the CCM for $\mathrm{NO}_{\mathrm{y}}$, inorganic chlorine $\mathrm{Cl}_{\mathrm{y}}$ and inorganic bromine $\mathrm{Br}_{\mathrm{y}}$ and as a stratospheric source for $\mathrm{CH}_{4}, \mathrm{~N}_{2} \mathrm{O}$, organic chlorine (CFC11, $\left.\mathrm{CFC} 12, \mathrm{CFC} 113, \mathrm{CCl}_{4}, \mathrm{CH}_{3} \mathrm{CCL}_{3}, \mathrm{CH}_{3} \mathrm{Cl}, \mathrm{HCFC} 22\right)$ and bromine $\left(\mathrm{CH}_{3} \mathrm{Br}, \mathrm{Ha} 1211\right.$, Ha1301). Concerning the ozone tropospheric chemistry in the model, our set up has several implications. First, it is important to acknowledge that a 2-
D model cannot allow for a proper treatment of tropospheric chemistry . However, we have checked that the 2-D model chemical fields for the present time did not differ substantially from the zonally averaged fields of the tropospheric chemistry version of our model (the LMDzT-INCA model described in Hauglustaine et al., 2004). We have used the 2 D model chemical fields here because LMDzT-INCA fields for the last 25 years were not available. Second, our set-up also results in a CCM that cannot be considered fully interactive with respect to tropospheric chemistry. Finally, the choice of the $400 \mathrm{hPa}$ level as the upper boundary for imposing the 2-D model chemical fields had some implications for our results that were not anticipated and that are discussed in the ozone results section.

Above $400 \mathrm{hPa}$, the chemical fields are calculated by the CCM. The evolution of stratospheric $\mathrm{Cl}_{\mathrm{y}}$ and $\mathrm{Br}_{\mathrm{y}}$ levels in response to the increase in $\mathrm{CFCs}$ and halons concentrations is explicitly calculated in the CCM. The time-varying global distribution of stratospheric sulphuric acid aerosols is also provided by the 2-D model ensuring that the chemical effects of enhanced aerosol loading following large volcanic eruptions is taken into account in the CCM simulation.

The CCM is initialised in 1975 with the 2-D model chemical fields. The mean amount of $\mathrm{Cl}_{\mathrm{y}}$ and $\mathrm{Br}_{\mathrm{y}}$ in the stratosphere in 1975 is $1.2 \mathrm{ppbv}$ and $10 \mathrm{pptv}$, respectively. The CCM is fully interactive, that is the model-calculated fields of water vapor, ozone, $\mathrm{CH}_{4}, \mathrm{~N}_{2} \mathrm{O}, \mathrm{CFC} 11$ and $\mathrm{CFC} 12$ are used as inputs in the radiation transfer calculations. $\mathrm{CO}_{2}$ mixing ratios used in the radiation transfer code are from the 2-D model. Monthly mean sea surface temperatures are prescribed according to the AMIP2 data for the period 19752000 (Taylor et al., 2000). We will only present and analyse the last 20 years of our simulation corresponding to the 1980-1999 period, the first five years being used as spin-up.

\section{Results}

\subsection{Dynamics}

To validate the dynamical performances of our model, we will mainly use 20-years (1980-1999) of the ERA40 ECMWF analysis (Simmons and Gibson, 2000).

\subsubsection{Zonal mean temperature}

In this section, monthly mean temperature fields for the last 20 -year of the simulation are examined. Figure 1 shows the January and July zonal mean temperature from the model and from the ERA40 ECMWF analysis. The model simulates a well-defined mid-latitude tropopause around $10 \mathrm{~km}$, a temperature minimum in the vertical around $100 \mathrm{hPa}$ in the tropics and in the winter polar lower stratosphere as well as a well-defined stratopause around $1 \mathrm{hPa}$. At this level, the temperature is maximal in the vertical for all latitudes and seasons, and the pole to pole meridional temperature gradient 

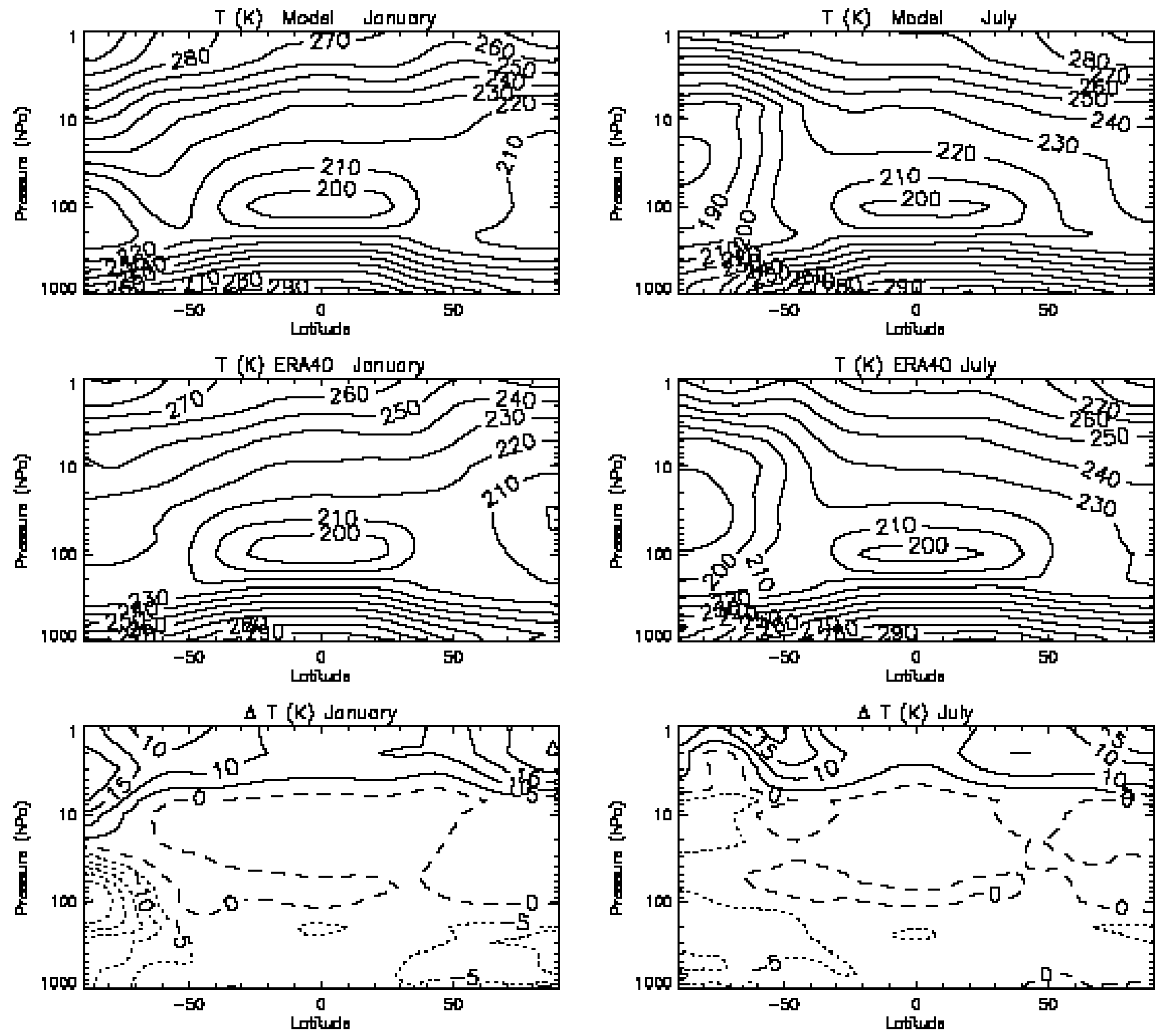

Fig. 1. January and July zonal mean distributions of the temperature for the period 1980-1999 from the LMDZ-REPROBUS model (top) and the ERA 40 ECMWF reanalysis (middle) and their differences shown in steps of $5 \mathrm{~K}$.

reverses during solstice seasons, presenting a local maximum at the summertime polar stratopause.

Although these features agree qualitatively with the observations, some pronounced model biases can be seen, when compared with the ECMWF reanalysis in Fig. 1. There is a warm bias around $10-15 \mathrm{~K}$ near everywhere at the stratopause. The polar winter stratosphere is typically 5 $10 \mathrm{~K}$ too cold in the Southern Hemisphere, but slightly too warm in the Northern Hemisphere. In October, the Southern Hemisphere polar lower stratosphere is again $20-40 \mathrm{~K}$ too cold (not shown). Figure 1 shows that a pronounced bias is still present in January with the vortex persisting. Note that, contrary to Lott et al. (2005), this simulation does not present a warm bias at the tropical tropopause, which is a clear indication that this bias in GCM was probably due to the specification of an ozone climatology that was not entirely correct in this region, and not to a problem of the model dynamics or of its radiation code.

\subsubsection{Stratospheric planetary waves and polar temperature}

Most of the stratospheric variability in the Northern Hemisphere arises from large-scale perturbations of the polar vortex by upward propagating planetary waves that originate in the troposphere (Charney and Drazin, 1961). Accordingly, 

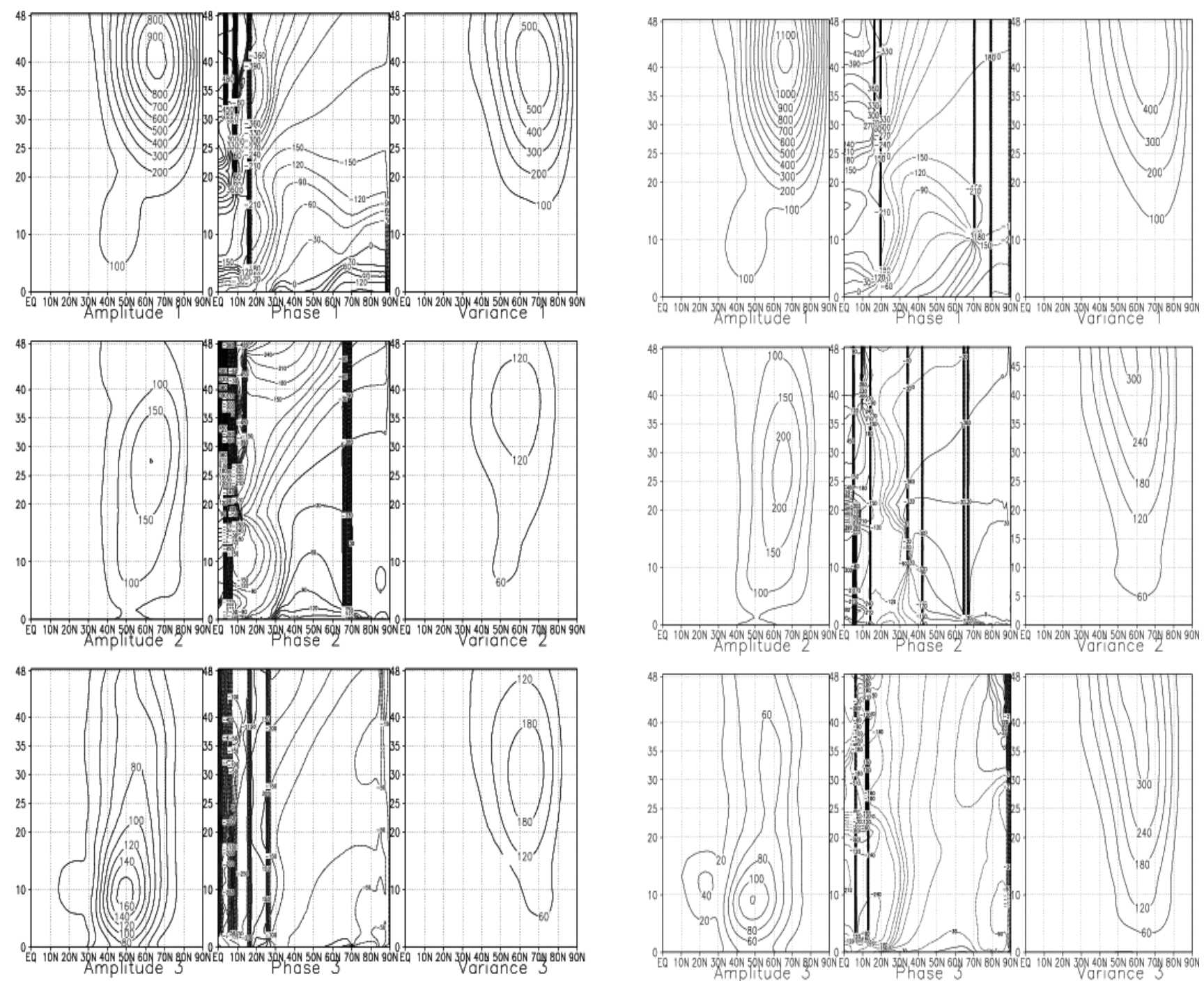

Fig. 2. January Planetary waves diagnostics of geopotential height fields for 20 winters for the LMDZ-REPROBUS model (left) and for ERA 40 reanalysis (right). Mean amplitude (left), mean phase (middle), intra-seasonnal standard deviation (right) are shown for waves with zonal wavenumber 1 (top row), 2 (middle row), 3 (bottom row).

a good representation of these planetary waves is essential for our stratospheric climate to be reasonable. The January statistics of the first 3 planetary waves from the model and from the reanalysis are shown in Fig. 2. Overall, it is clear that the rather realistic simulations of the zonal mean fields and tropospheric climate result in the forcing of planetary waves that are both realistic in phase and amplitude. Note nevertheless that the model has a tendency to underestimate the amplitude and variability of the first 3 planetary waves in the Northern Hemisphere. It is interesting to notice here that those results are opposite to those in Lott et al. (2005) who found that the Stratospheric version of LMDz tends to slightly overestimate the Planetary Waves (PWs) in the Northern Hemisphere winter (see Figs. 6 and 7 in Lott et al., 2005). Sensitivity tests done over a shorter period than that documented here, suggest that this is due to the change in the parameter $\beta$ if the Subgrid Scale Orography scheme described in Sect. 2. Otherwise, the slightly too cold North Pole temperature found in Lott et al. (2005) (see their Figs. 1 and 13) leads to the formation of too many PSCs and hence to a too pronounced ozone destruction from PSCs heterogeneous chemistry. This change yields to a more realistic zonal mean temperature, but also yields to a smaller planetary wave variability. Note nevertheless that the model now overestimates the Northern polar temperature by $5 \mathrm{~K}$ in winter. The general tendency for the model to underestimate the PWs variability is also found in the Southern Hemisphere (not shown). As the PWs were slightly overestimated in the 

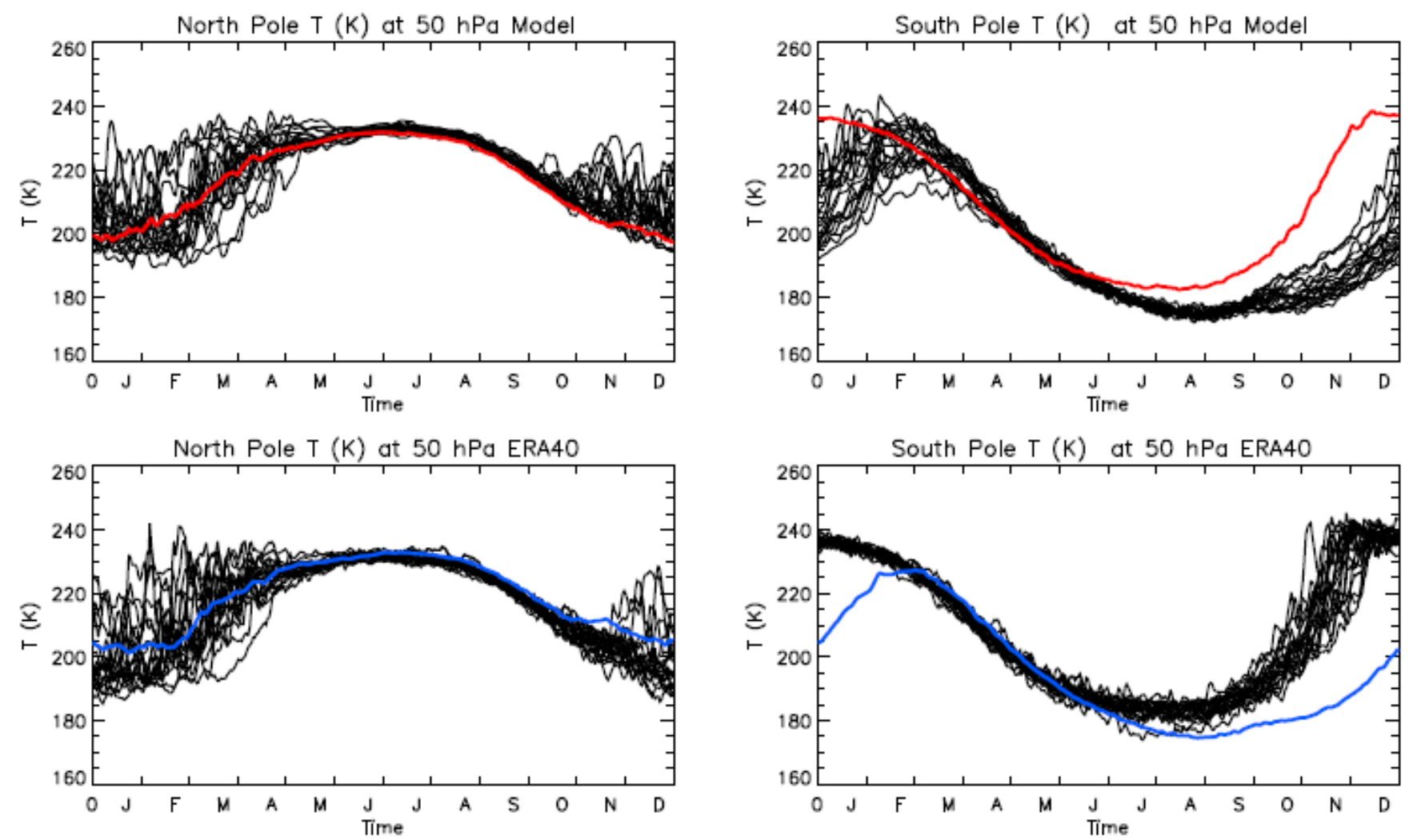

Fig. 3. Polar temperatures at 50hPa and for 20 years (1980-1999) in LMDz (top) and in the ERA 40 ECMWF reanalysis (bottom) for the Northern Hemisphere (right), and the Southern Hemisphere (left). The mean value over the 20 years are in red for ECMWF reanalysis and in blue for LMDz.

Southern Hemisphere as well in Lott et al. (2005) we found here a sensitivity to the subgrid scale mountain gravity waves in the Southern Hemisphere that we did not expect.

Figure 3 shows the seasonal cycle of the stratosphere temperatures over the poles at $50 \mathrm{hPa}$ from the model and from the ERA 40 ECMWF reanalysis. The model captures the general nature of the temperature variations, their seasonal dependence and the contrasts between the two hemispheres. However, the model has a slight warm bias of around 5-10 K at the North Pole and a pronounced cold bias at the South Pole in late winter to early summer that can reach up to $40 \mathrm{~K}$. Figure 3 shows that the model exhibits a $5-10 \mathrm{~K}$ cold bias at the South Pole in July that was already present in the GCM version of the model (see Figs. 1 and 2 in Lott et al., 2005). This bias increases throughout spring because the vortex persists too long in the simulation. Figure 3 also shows that the model Northern Hemisphere polar temperature displayed an interannual variability in agreement with the reanalysis. In particular, the stratospheric warmings in the model occur throughout the winter, and the vortex can reconstruct after a warming. In spring, the interannual variability in the South Pole temperature at $50 \mathrm{hPa}$ is smaller in our simulation than in the reanalysis. In early summer, it is significantly larger in our simulation than in the reanalysis. Indeed, polar ozone destruction still occurs in early summer in our simulation and its interannual variability contributes to the polar temperature variability.

Although the LMDz-REPROBUS simulation is in generally good agreement with ERA 40 reanalysis, the Southern Hemisphere suffers from the common cold pole bias: the polar vortex is too strong and persists too long during the year until early summer. This bias is more pronounced than in Lott et al. (2005) where ozone concentration fields are specified via climatologies. Accordingly, we attribute the strong cold bias in the Southern Hemisphere Temperature at the pole to a retroaction of the chemistry. This will be illustrated in Sect. 3.3.

\subsection{Transport}

In this section, we present conventional diagnostics of the transport in our simulation.

\subsubsection{Mean age of air}

To calculate the mean age of the air in the stratosphere, we follow Hall and Prather (1993) and include in the model an inert tracer whose concentration grows linearly with time 

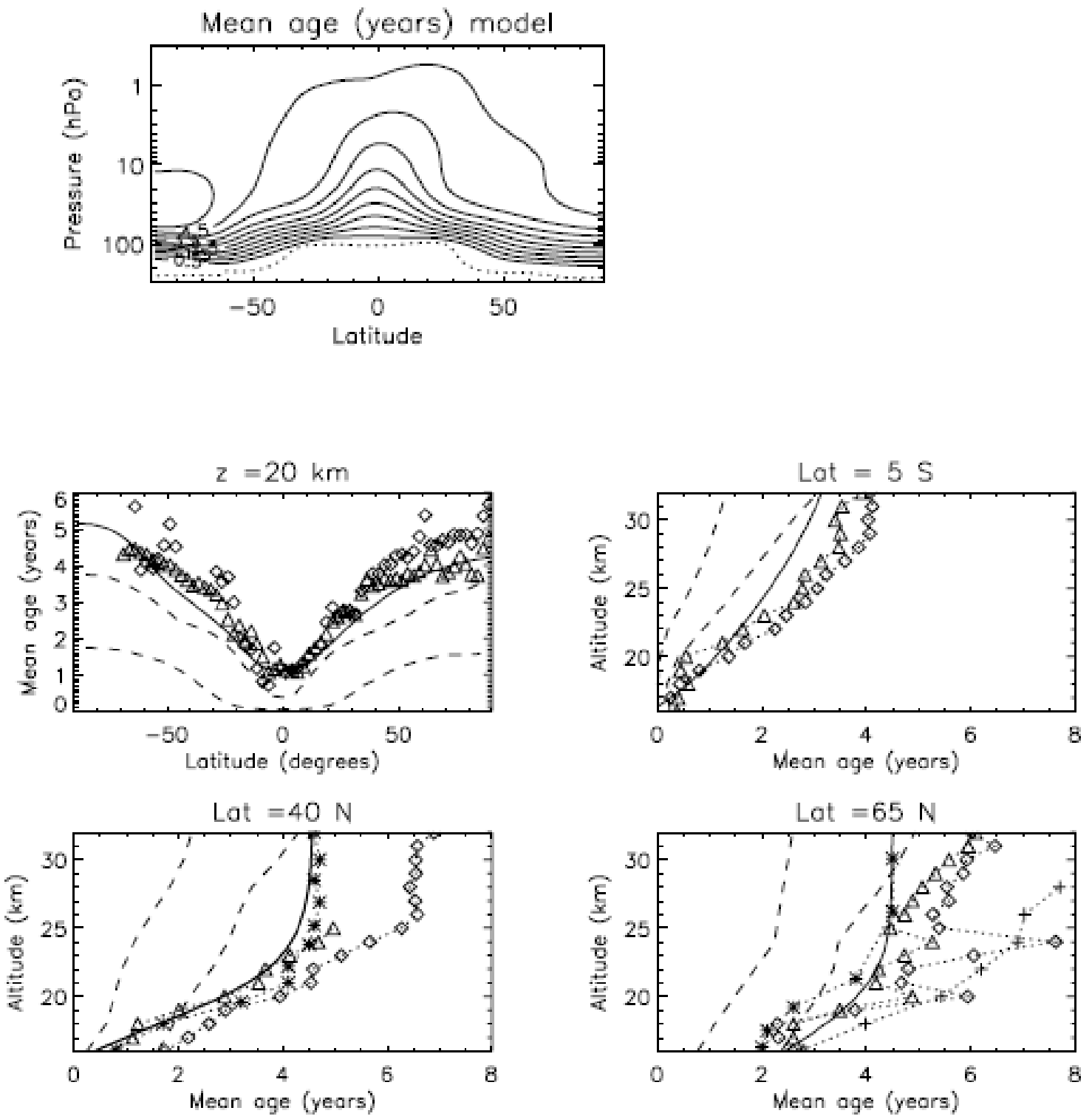

Fig. 4. Annually and zonally averaged mean age of air relative to the equatorial tropopause and after 20-years of the LMDz-REPROBUS simulation (see text for details). (a) Latitude-altitude section, the dotted thick line indicates the thermal tropopause and the contour interval is 0.5 year.; (b) Latitudinal variation at the altitude $z=20 \mathrm{~km}$. (c) vertical profile at the latitude $5 \mathrm{~S}$, (d) vertical profile at the latitude $40 \mathrm{~N}$, and (e) vertical profile at the latitude $65 \mathrm{~N}$. In (b), (c), (d), and (e) the solid line is for the model values while the various symbols are derived from observations: in situ $\mathrm{CO}_{2}$ (triangles) are from Boering et al. (1996) and Andrews et al. (2001b), in situ SF6 (diamonds) are from Elkins et al. (1999), Ray et al. (1999) and SF6 whole-air samples are from Harnish et al. (1996) (asterix outside the vortex and crosses inside the vortex). See also Hall et al. (1999) for details on those measurements. The dashed lines represent the range of most models involved in the Models and Measurements II project (Hall et al., 1999).

below a given lower boundary. In the present study, this boundary is the equatorial tropopause between $15^{\circ} \mathrm{N}$ and $15^{\circ} \mathrm{S}$ and the mean age of air at a given point in the stratosphere is derived from the difference between the mixing ratio of this tracer at that point and its mixing ratio at the tropical tropopause. The time lag is calculated after 20 years of simulation.
Figure 4a shows the zonally and annually averaged mean age in our simulation. In it, we see that the isopleths of the mean age bulge upward in the tropics and slope downward to the poles as a result of the Brewer-Dobson meridional circulation. The quasi-horizontal mixing by the planetary scale wave "breaking" is also clearly apparent in the flattening of the isopleths at midlatitudes (see Fig. 4a). 

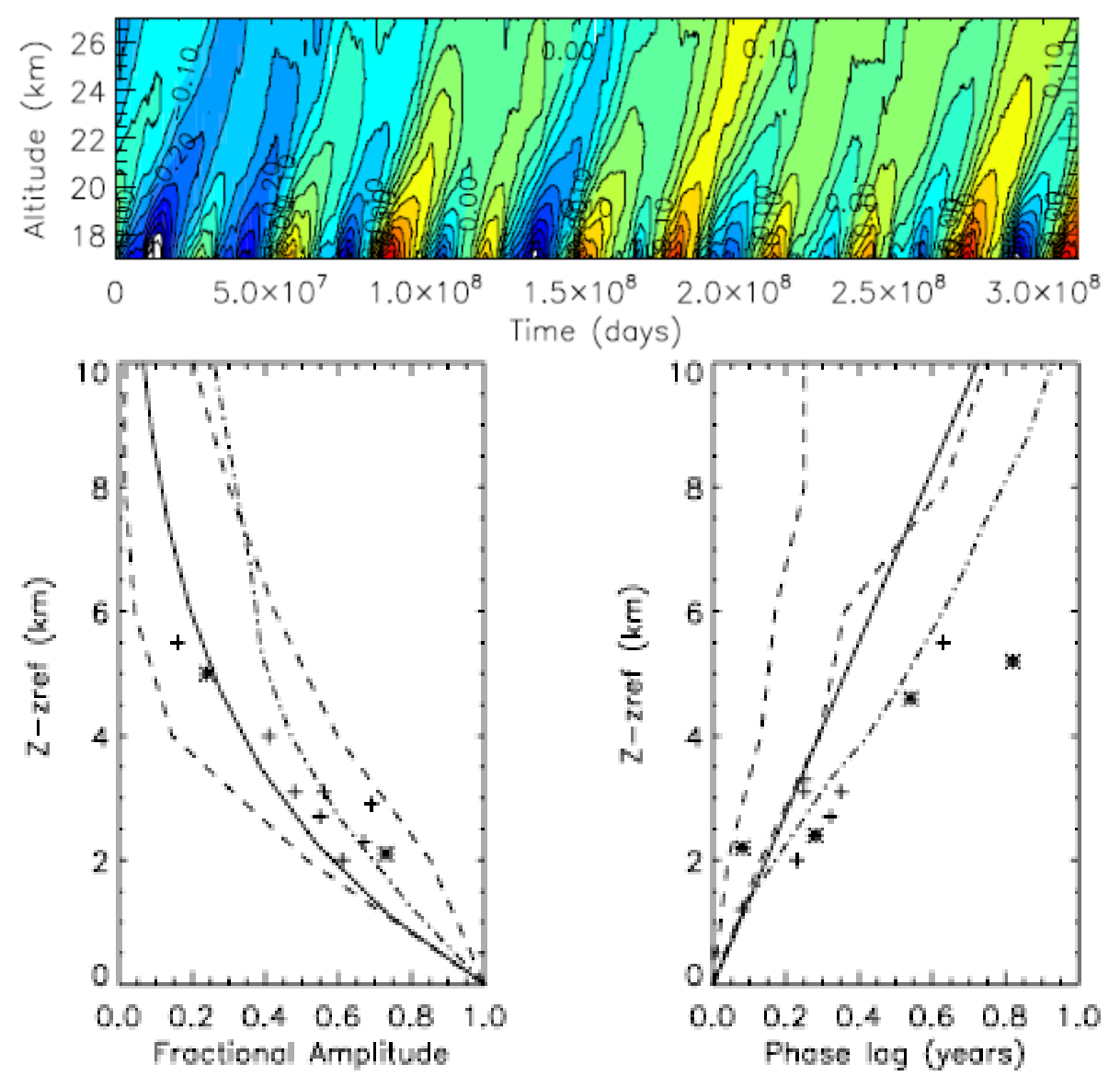

Fig. 5. Time-altitude cross section of total hydrogen $\mathrm{H}\left(=2 \mathrm{CH}_{4}+\mathrm{H}_{2} \mathrm{O}\right)$ simulated by LMDz-REPROBUS for the 1986-1995 period, shown as the deviation from the mean time profile, averaged between $12 \mathrm{~S}$ and $12 \mathrm{~N}$ (top). Equatorial profiles of the amplitude attenuation $A(z)$ (bottom left) and the phase lag $\tau(z)$ (bottom right) of the tape recorder in the lower and middle troposphere derived from in situ $\mathrm{CO}_{2}$ (crosses), in situ $\mathrm{H}$ (stars) and HALOE H (dashed-dotted line) as reported in Hall et al. (1999) and from the analysis of the simulated H anomalies field shown in the upper panel (solid black line). The altitude (zref) where the amplitude attenuation and the phase lag are equal to 1 and 0 , respectively, is at $16 \mathrm{~km}$ for the observations and $17 \mathrm{~km}$ for the model. Note that our results are different than in Eyring et al. (2006) (see text for more details).

In Fig. 4b-e, the annually averaged mean age of air in the simulation is evaluated more thoroughly by comparison with estimates from the SF6 and CO2 observations reported by Hall et al. (1999). Figure $4 \mathrm{~b}$ shows that in the low stratosphere the model reproduces very well the latitudinal distribution of the mean age of air. The vertical profile of the mean age of air in the tropics (Fig. 4c) is also well reproduced, but the air is a year too young above $22 \mathrm{~km}$. As reported by Waugh and Hall (2002), several factors could contribute to decrease the mean age of air in this region as a too rapid meridional circulation, a too weak mixing with midlatitudes air or too much vertical diffusion (explicit or numerical). We have not performed model sensitivity studies to theses different aspects of the transport. This limits our ability to draw definitive conclusions on the reasons of the discrepancies. However, we can note that the model appears to reproduce the shift between the tropical and the extratropical profiles of the mean age of air (Fig. $4 \mathrm{c}$ and d, respectively) as well as the steep latitudinal gradient of the mean age in the lower stratosphere (Fig. 4b), suggesting a correct isolation of the tropics in our simulation. This aspect is further investigated later on.

At middle and high Northern latitudes in the low stratosphere, (Fig. 4d and e, respectively) the model age of air increases with altitude in agreement with the observations. Note that this increase is the result of the quasi-horizontal wave-driven mixing, because the transport by the mean residual circulation alone would tend to produce the highest values of the age of air in the lower stratosphere at high latitudes (Waugh and Hall, 2002). On the contrary, the model simulates a pronounced maximum in the polar lower stratosphere in the Southern Hemisphere, consistent with the weaker quasi-horizontal mixing in this hemisphere (Fig. 4a). Again, 

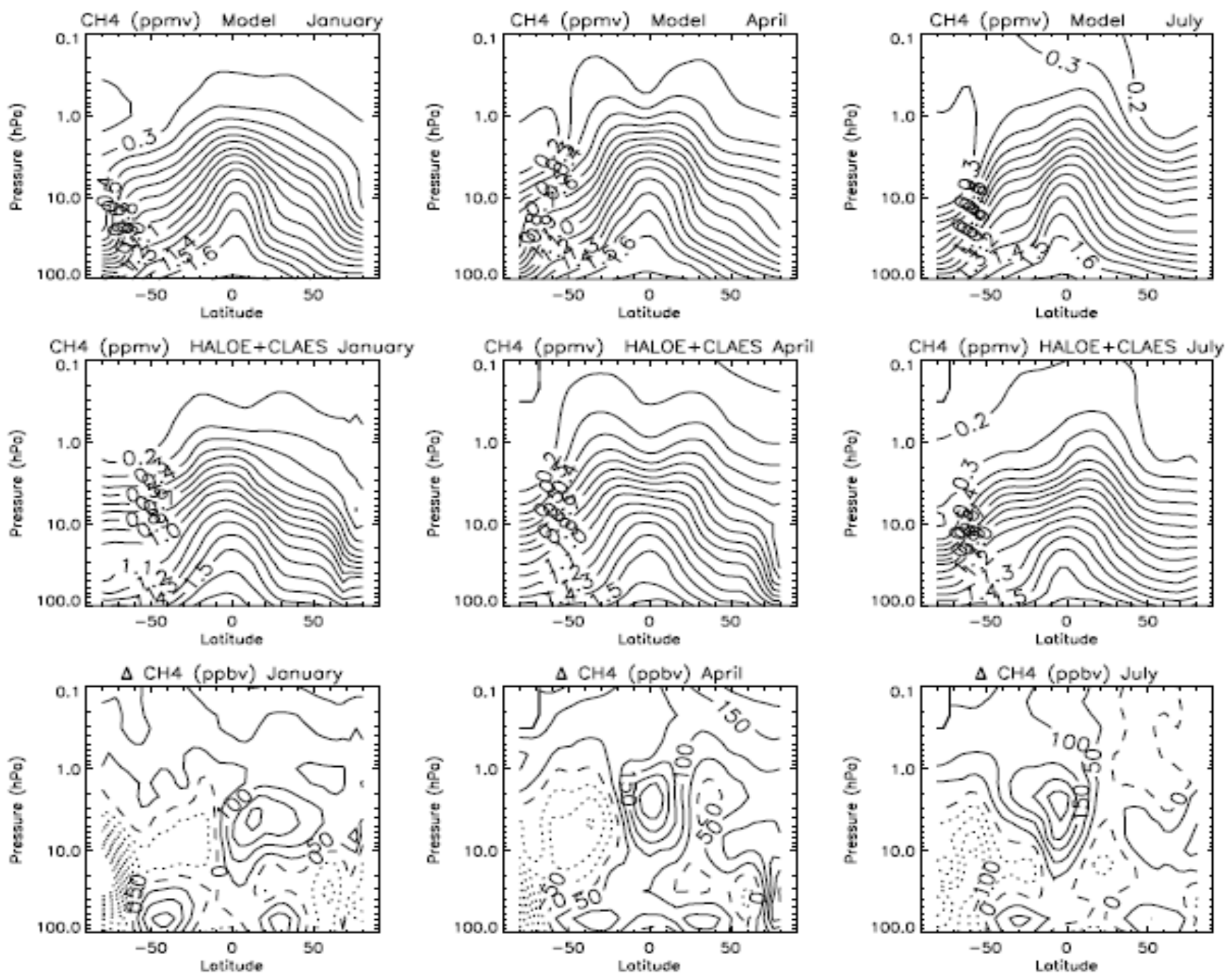

Fig. 6. January, April and July zonal mean distributions of $\mathrm{CH}_{4}$ mixing ratios (ppmv) simulated by the model for the period 1991-1997 (top), observed by HALOE and CLAES (middle) and their differences (bottom).

the model nevertheless underestimates the mean age of air at high latitudes of the Northern Hemisphere above $25 \mathrm{~km}$. This discrepancy is particularly pronounced inside the polar vortex (Fig. 4e), where observations indicate values greater than 7 (instead of 4 years in our simulation).

Overall, the model does reproduce the latitudinal and vertical variation of the mean age of air reasonably well. We find that the transport in our model is more realistic than in most of the models evaluated within the framework of the Models and Measurements II project presented in Hall et al. (1999) (dashed lines in Fig. 4b-d). The main remaining discrepancy is that the air tends to be too young by 1 to 3 years in the middle and upper stratosphere. The same conclusions were found in Eyring et al. (2006) for the most recent state of the art CCMs.

\subsubsection{Tape recorder signal}

The seasonal temperature changes at the equatorial tropopause induce a seasonal variation of the water vapor entering into the lower tropical stratosphere. The vertical propagation of this water vapor seasonal cycle is the "tape recorder" (Mote et al., 1995, 1996). The analysis of this signal provides informations on the ascent rate and on the diffusion in the tropical upwelling as well as on the intensity of the mixing with the extratropical air. In the following, we use the variable part of the total hydrogen $\mathrm{H}=2 \mathrm{CH}_{4}+\mathrm{H}_{2} \mathrm{O}$, that is better conserved than water vapor (John et al., 1986), to analyse the tape recorder signal in the model simulations.

Figure 5 presents the model-calculated $\mathrm{H}$ deviation from the mean time equatorial profile as a function of altitude and time. The model reproduces the typical seasonal variation of 

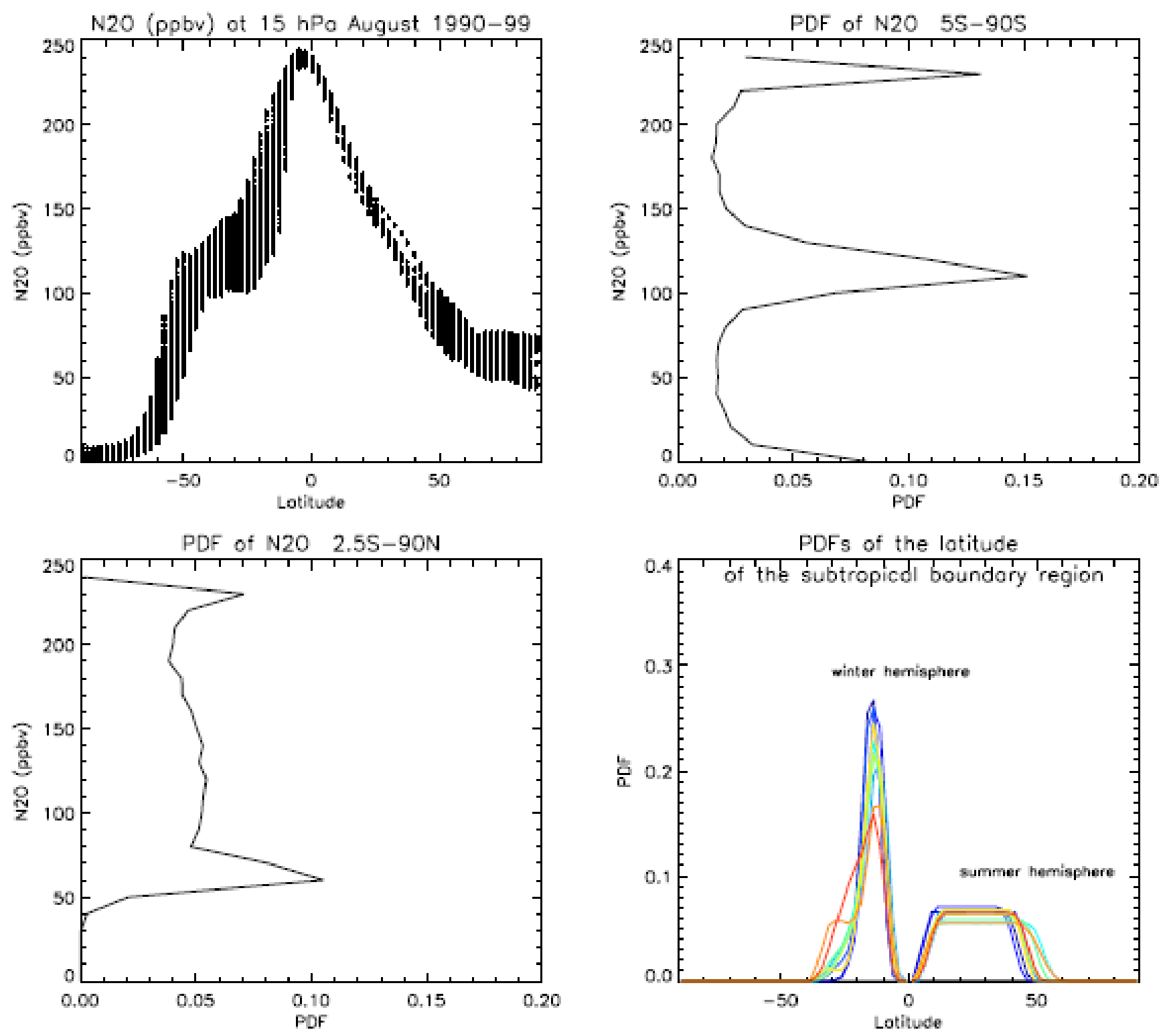

Fig. 7. Latitudinal distribution of the simulated $\mathrm{N}_{2} \mathrm{O}$ mixing ratios at $15 \mathrm{hPa}$ in August for 1990-1999 (top left). Area weighted PDF of the $\mathrm{N} 2 \mathrm{O}$ mixing ratios for the winter hemisphere (top right) and for the summer hemisphere (bottom left). PDF of the latitude of the subtropical boundary region (bottom right) for the winter and summer hemispheres for each year from 1990 (blue) to 1999 (red).

$\mathrm{H}$ at the equatorial tropopause with a minimum during boreal winter and a maximum during boreal summer. In order to determine the variation of the amplitude $(A)$ and the phase lag $(\tau)$ of the tape recorder propagation, the simulated $\mathrm{H}$ profiles (Fig. 5) are fitted to the function,

$X(z, t)=A(z) \cos (\omega(t-\tau(z))$,

using the Levenberg-Marquardt least square fit algorithm. The amplitude is assumed to decay exponentially with the altitude: $A(z)=A_{o} e-z / H_{a}$, with $A_{o}$, the maximum amplitude of the signal and $H_{a}$ the decay scale height, indicating of the attenuation rate of the tape recorder signal with altitude. The ascension rate $c$ is supposed to be constant, giving a phase lag $\tau(z)=z / c$. In Fig. 5, our results are also compared with estimates derived from the analysis of $\mathrm{H}$ observations from the Halogen Occultation Experiment (HALOE) instrument on the Upper Atmospheric Research Satellite (UARS) by Mote et al. (1998) and from in situ aircraft and balloon measurements of $\mathrm{CO}_{2}$ and $\mathrm{H}$ reported in Hall et al. (1999). Note that in order to compare the model-calculated signal and observations, we normalize the amplitude to unity at a reference level (Fig. 5), which is $17 \mathrm{~km}$ for the model and 

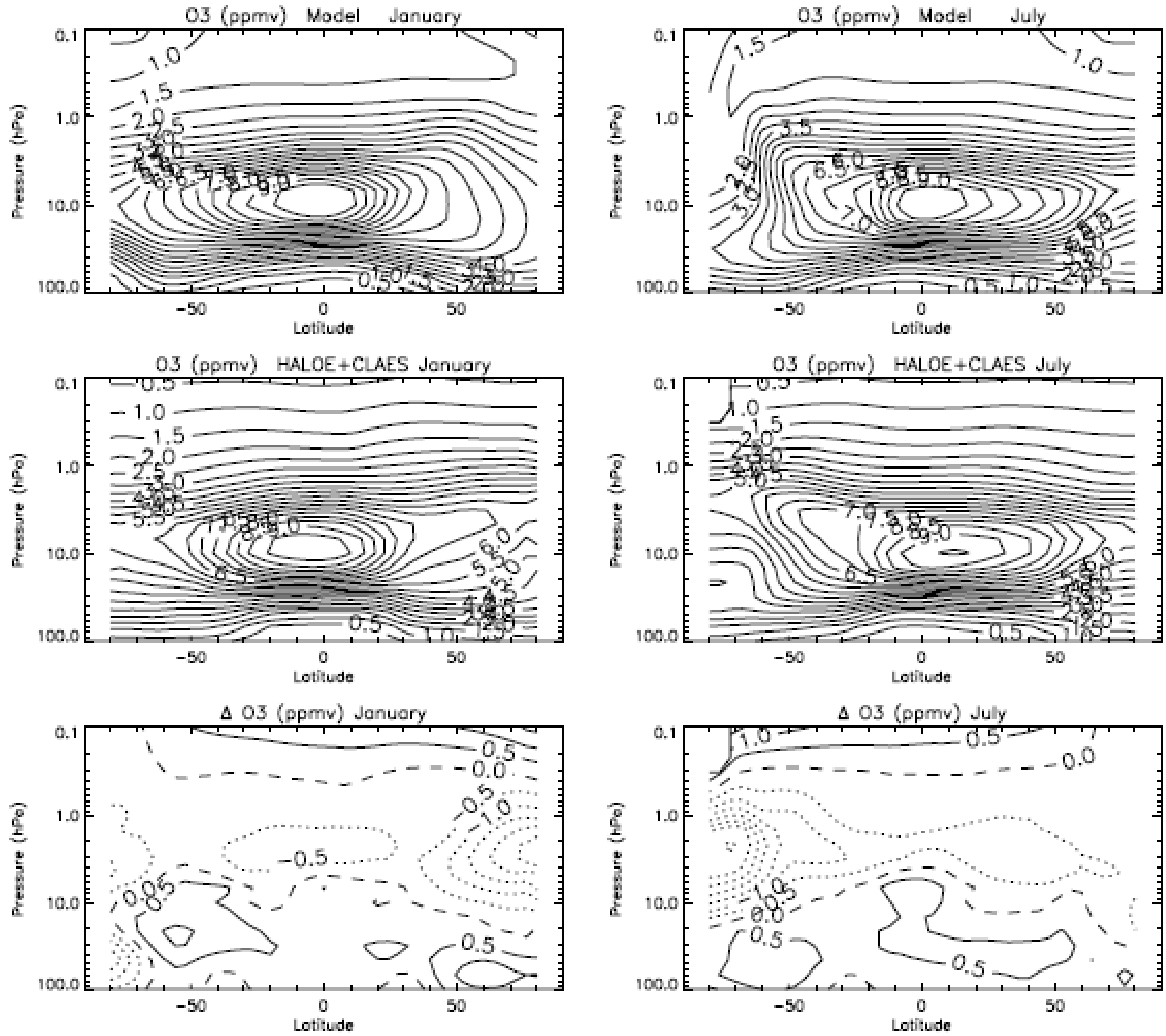

Fig. 8. January and July zonal mean distributions of $\mathrm{O}_{3}$ mixing ratios (ppmv) simulated by the model for the period 1991-1997 (top), observed by HALOE and MLS (middle) and their differences shown in steps of 0.5 ppmv.

$16 \mathrm{~km}$ for the observations as in Hall et al. (1999). The phase $\operatorname{lag} \tau$ is also taken null at this reference level (zref).

The model slightly underestimates the phase lag in the low stratosphere which is about 0.6 years at $\mathrm{z}$-zref $=8 \mathrm{~km}$ whereas the analyses of Mote et al. (1998) and Randell et al. (1998) of the HALOE data give 0.8 years and of 0.9 years, respectively, at the same level. The model mean ascent rate over the first $10 \mathrm{~km}$ of the lower stratosphere is about $0.44 \mathrm{~mm} / \mathrm{s}$, which is higher than the corresponding value of $0.3 \mathrm{~mm} / \mathrm{s} \mathrm{es}-$ timated by Mote et al. (1998). Figure 5 also suggests that the model slightly overestimates the attenuation of the amplitude A with the altitude. The decay scale height $H_{a}$ of the amplitude is found to be about $3.7 \mathrm{~km}$. Note that Eyring et al. (2006) found that our model-calculated tape recorder signal was decaying much too rapidly compared to the observations and other CCMs (see their Fig. 6). This is different from the results obtained here with the same methodology. This is due too the fact that we do not use the same reference altitude, zref, as in Eyring et al. (2006) (V. Eyring and D. Waugh, personal communication). Eyring et al. (2006) choose zref as the level of the maximum amplitude for the model-calculated signal above $100 \mathrm{hPa}$. For the part of the cycle when the altitude of the tropopause is higher, negative anomalies (expected) in the stratosphere are associated with 

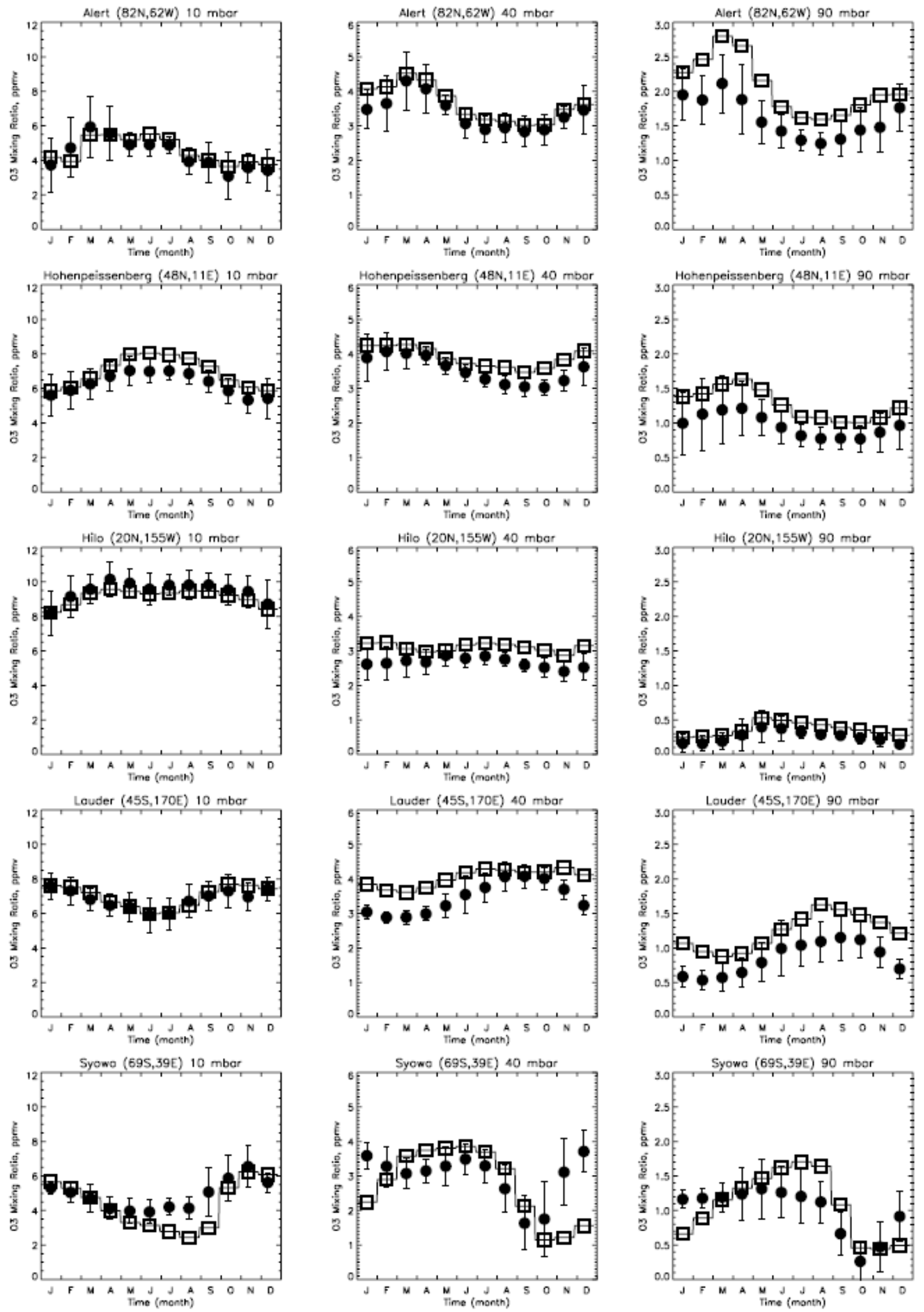

Fig. 9. Seasonal variation of $\mathrm{O}_{3}$ mixing ratios (ppmv) over different stations measured by sondes and simulated by the model. Measurements (black dots) and simulated mixing ratios (open squares) are averaged over the period 1986-1995. Note that the standard deviation for the model is not shown as for practical reasons we archived 5-day average outputs for most of the years of simulation. 
positive anomalies in the model just above the tropopause $(\sim 100 \mathrm{hPa})$ and vice versa for the other part of the cycle. When the reference altitude is set to $100 \mathrm{hPa}$, these positive anomalies just above $100 \mathrm{hPa}$ give the impression that the vertical decay is much faster, as in Eyring et al. (2006). To avoid this problem, we start fitting our data just above these anomalies, at about $17 \mathrm{~km}$. Our tape recorder values are now found in the same range as most of the models evaluated in Eyring et al. (2006). Also, our results on the tape recorder signal are more consistent with the mean age of air and methane distributions.

Overall, the results indicate that the model tends to propagate the tape recorder too fast (by about $30 \%$ ), which is consistent with our underestimation of the age of air in the tropics (Fig. 4c). The model also tends to attenuate slightly too much the amplitude of the tape recorder. This latter discrepancy could be due to too much mixing between extratropics and tropics but this problem was not revealed by our analysis of the mean age of air distribution (see Sect. 3.2.1). This discrepancy could also be due to too much vertical diffusion in the upwelling (in our case numerical diffusion due too the transport scheme, the explicit diffusion occurring only in the boundary layer in the model). This could explain as well the too young mean age of air in the tropics. However, as noted by Hall et al. (1999) and Waugh and Hall (2002), it is difficult to sort out the reasons of the discrepancies without performing sensitivities studies to the different aspects of the transport.

\subsubsection{Long-lived species}

In this part, we examine the CCM's distribution of $\mathrm{CH}_{4}$ and $\mathrm{N}_{2} \mathrm{O}$. Figure 6 shows the comparison between the January, April and July zonal mean distributions of $\mathrm{CH}_{4}$ simulated by the LMDz-REPROBUS model for the 1991-1997 period and the corresponding values derived from the Halogen Occultation Experiment (HALOE) and the Cryogenic Limb Array Etalon Spectrometer (CLAES) on the Upper Atmospheric Research Satellite (UARS). The HALOE data (version 18) covers the period November 1991-March 1997 and have been combined with CLAES data obtained between January 1992 and March 1993 in the polar regions (Randell et al., 1998). This climatology is available on the SPARC Data Center (http://www.sparc.sunysb.edu/).

Figure 6 shows that the model is able to reproduce most of the main typical features of the zonal mean distribution of long-lived species; as expected, the distributions are consistent with the zonal fields of the mean age of air (Sect. 3.2.1 and Fig. 4a). This figure also shows that the model tends to overestimate the methane mixing ratios in the middle and upper stratosphere, by up to $250 \mathrm{ppbv}$ in the equatorial region during the equinox and in the tropical regions of the winter hemisphere otherwise. During the equinox, this deficiency is clearly due to the absence of a double peak that is present in the observations below 1 mbar. This is related to the absence of the QBO in the model, which simulates only easterlies in the tropics. Indeed, Kennaugh et al. (1997) and Randel et al. (1997) found that the double peak in the $\mathrm{CH}_{4}$ observations is weak or even inexistent when the phase of the QBO corresponds to easterlies. The differences in January and July are more difficult to explain. But, again, the absence of the QBO in the model could also contribute to the discrepancies. During the westerly phase of QBO, there is also a shift of the winter hemisphere edge of the high $\mathrm{CH}_{4}$ values isopheths toward the equator and more mixing in the subtropics during winter (Neu et al., 2003). The model overestimates the methane mixing ratios in the subtropics of the winter hemisphere in January and July with $\mathrm{CH}_{4}$ isopleths being flatter in the observations. We can also note that the model also underestimates the $\mathrm{CH}_{4}$ mixing ratios at high latitudes in the Southern Hemisphere, in particular in January, by up to $500 \mathrm{ppbv}$, confirming the too strong isolation of the polar vortex in winter and the delay of its break-up until summer.

In order to investigate further the isolation of the tropical regions in the model, we have also evaluated the position and extent of the subtropical boundary in the model following Sparling et al. (2000) and Neu et al. (2003). Figure 7 shows the latitudinal distribution of $\mathrm{N}_{2} \mathrm{O}$ mixing ratios at $15 \mathrm{hPa}$ for August 1990-1999 and the corresponding area-weighted probability density functions (PDFs) of $\mathrm{N}_{2} \mathrm{O}$ mixing ratios at this level in the Northern and Southern Hemisphere. $\mathrm{N}_{2} \mathrm{O}$ mixing ratios are binned on $5 \mathrm{ppbv}$ intervals and the PDFs are smoothed with a $5 \mathrm{ppbv}$ running average. The Northern and Southern Hemispheres are separated according to the latitude of the tropical maximum. This Fig. 7 can be compared to the PDFs of $\mathrm{N}_{2} \mathrm{O}$ mixing ratios obtained with CLAES observations for August 1992 by Sparling et al. (2000) (see their Fig. 3). The peaks in the distribution reveal the presence of three distinct air masses in the winter hemisphere (Southern Hemisphere) corresponding to the tropics, the midlatitudes surfzone, and the polar vortex, and two distinct air masses in the summer hemisphere (Northern Hemisphere) corresponding to the tropics and the extratropics. The minima of the distribution correspond to the transition regions between the different types of air masses. We focus here on the subtropical transition regions. We have calculated for each hemisphere and for each year the PDFs of the latitude corresponding to $\mathrm{N}_{2} \mathrm{O}$ values in the subtropical transition regions, using the same approach than Neu et al. (2003). We define the latitude of the subtropical boundary as the most probable latitude and we interpret the width of the distribution as a measure of the extent of the transition regions following Neu et al. (2003).

For the winter hemisphere, we find that the subtropical transition region is very narrow and that the most probable position of the subtropical barrier at $15 \mathrm{hPa}$ ranges between $11.25 \mathrm{~S}$ and $13.75 \mathrm{~S}$ depending on the year. For the summer hemisphere, the subtropical transition region is very large from $8.75-13.75 \mathrm{~N}$ to $33.75-43.75 \mathrm{~N}$ depending on the year. These results are comparable with those derived from 

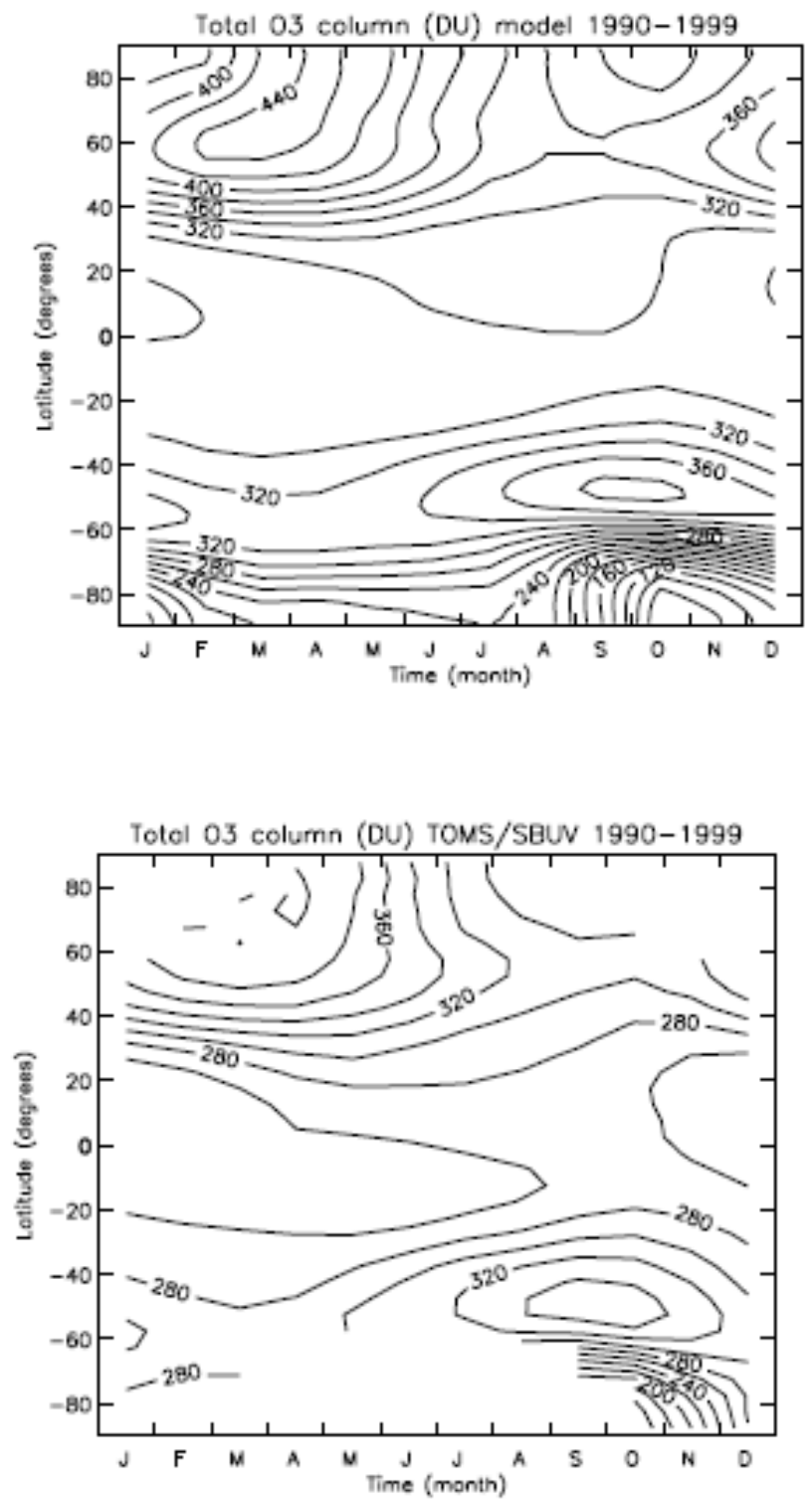

Fig. 10. Variation of total ozone (in Dobson unit) with latitude and time (month); top panel: mean value for the last 10 years of the simulation (1990-1999), bottom panel: mean value of TOMS/SBUV observations for the period 1990-1999.

the analysis of the CLAES and HALOE observations (Sparling et al., 2001; Neu et al., 2003). Note that we could not determine a value for the summer subtropical boundary as the transition is gradual in our simulation. However, the position center of the subtropical region is comparable with the position of the subtropical barrier in the studies cited above. Overall, this shows that the model correctly reproduces the positions and the extents of the subtropical transition regions in the middle stratosphere.

\subsection{Distributions of chemically reactive species}

\subsubsection{Ozone}

The vertical and seasonal variation of ozone mixing ratios in the stratosphere have been evaluated using a climatology which combines HALOE and Microwave Limb Sounder (MLS) satellite data (Randel et al., 1998) and in situ measurements over several ozonesondes stations from the World Ozone and Ultraviolet Radiation Data Centre (WOUDC) for the period 1986-1995. Figure 8 shows that the model reproduces correctly the maximum of about $10 \mathrm{ppmv}$ near $10 \mathrm{hPa}$ in the tropics, as well as its slight seasonal shift toward the summer hemisphere. The difference in ozone mixing ration between the model simulations and observations is generally within $0.5 \mathrm{ppmv}$, except at high latitudes in the upper stratosphere in the winter hemisphere where the difference can reach up to 3 ppmv. These differences in the winter hemisphere are likely to be due to shortcomings in the transport and dynamics in our simulation. Indeed, in the Northern Hemisphere in January, the slopes of the ozone isopleths, downward from the equator to the pole, are steeper in the model than in the observations, suggesting too much wave forcing. In the Southern Hemisphere extratropics in July, the sharp decline in the ozone mixing ratios with decreasing latitude confirms the too strong isolation of the vortex. Note, that these differences in the shape of the isopleths contribute to attenuate the typical "ozone smile" feature in the middle and upper stratosphere in the model compared to observations.

The seasonal cycle of $\mathrm{O}_{3}$ in the lower and middle stratosphere is evaluated in more detail with comparisons with ozonesondes measurements in Fig. 9. The model reproduces correctly the weak seasonal cycle in the tropics. At middle and high latitudes, the maximum in the middle stratosphere $(10 \mathrm{hPa})$ in the summer hemisphere (due to the chemistry) and the spring maximum in the lower stratosphere (at $40 \mathrm{hPa}$ and $90 \mathrm{hPa}$ ) (that is due to the transport) are also well reproduced. The model overestimates the ozone mixing ratios in the middle and lower stratosphere in the Southern Hemisphere midlatitudes (Lauder, $45 \mathrm{~S}$ ). This discrepancy is consistent with the reduced transport from middle to high latitudes in this hemisphere due to the strong isolation of the vortex. Over Syowa (69 S), the model underestimates the ozone concentrations at $40 \mathrm{hPa}$ in spring and early summer. This results from the cold bias at high latitudes in the Southern Hemisphere in winter and spring (Fig. 3), leading to excessive PSC formation and subsequent ozone destruction. This in turn contributes to maintain low temperatures and the vortex until early summer and consequently delay the ozone recovery. We can also note that the model tends to overestimate the ozone mixing ratios in the lowermost stratosphere over Alert $(82 \mathrm{~N})$ and Hohenpeissenberg $(48 \mathrm{~N})$. This discrepancy results from a slightly too strong transport from the region of production. 

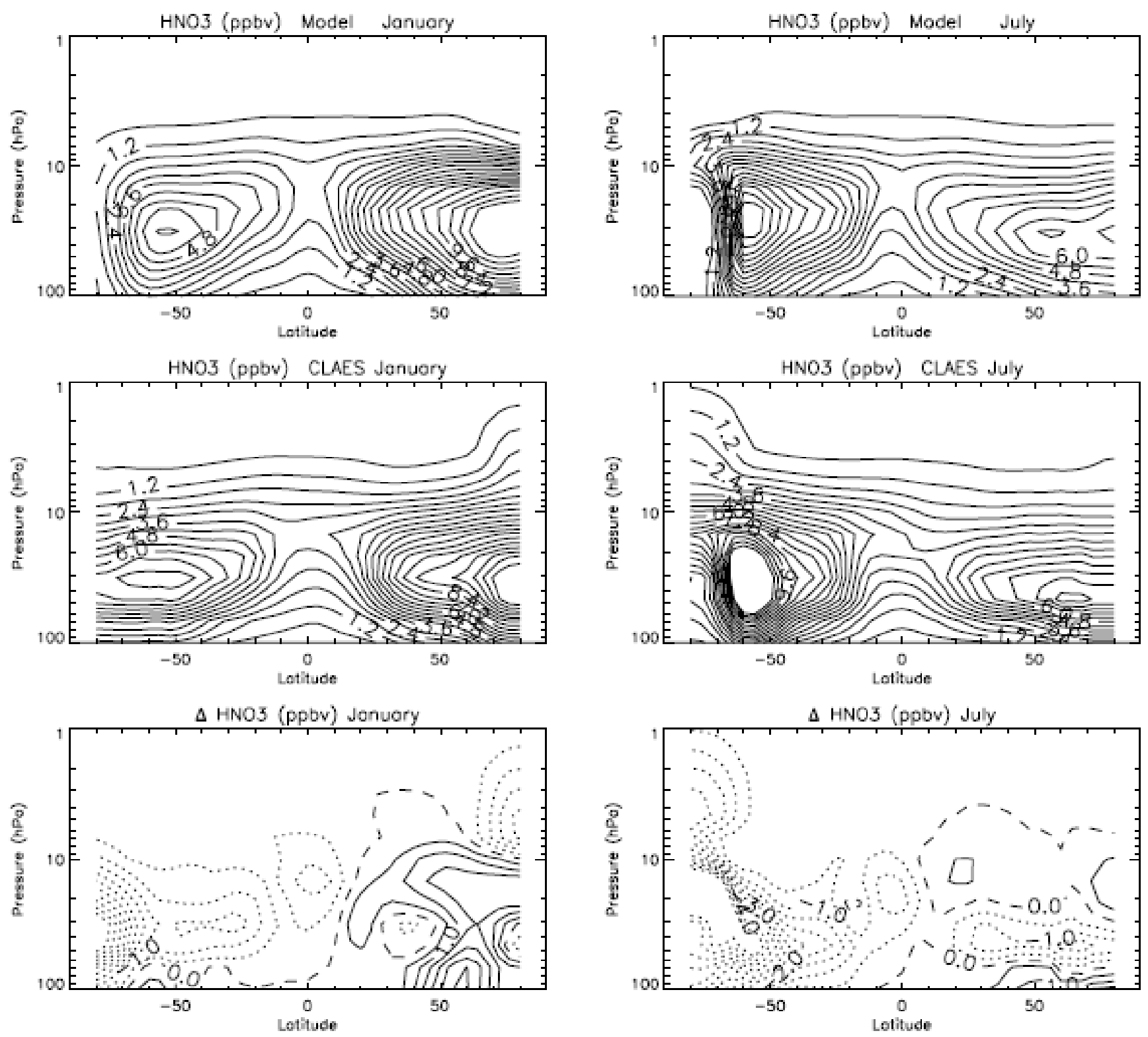

Fig. 11. January and July zonal mean distributions of $\mathrm{HNO}_{3}$ mixing ratios (ppbv) simulated by the model for the year with the forcing of 1992 (top), observed by CLAES in 1992 (middle) and their differences shown in steps of 0.5 ppbv.

The Total Ozone Column has also been examined by comparing the modeled values with the merged TOMS/SBUV dataset (http://code916.gsfc.nasa.gov/Data_services/merged/ index.html) for the period 1990-2000 (Fig. 10). The variation of the total ozone column reflects the variation of the ozone concentrations in the lower and middle stratospheric, presented and discussed previously. Figure 10 also shows that the total ozone values in the tropics are overestimated by up to about $40 \mathrm{DU}$. As the agreement with tropical ozonesondes is satisfactory in the lower and middle stratosphere, this discrepancy is in fact due to an overestimation of the tropospheric ozone column. This problem originates from the difficulty in maintaining the strong vertical gradients of ozone in the tropopause region. It is important to note that since the model is relaxed below 400 mbar toward the 2-D model ozone fields (see Sect. 2), this problem has a significant impact only in the tropical and subtropical regions, where the tropopause is situated well above 400 mbar all the year around. In these regions, the ozone amount between $400 \mathrm{mbar}$ and the tropopause increases during the simulation. Indeed, tropospheric ozone columns of 50 DU are simulated on average in the tropics for the last year of the simulation (not shown), which is too high. 

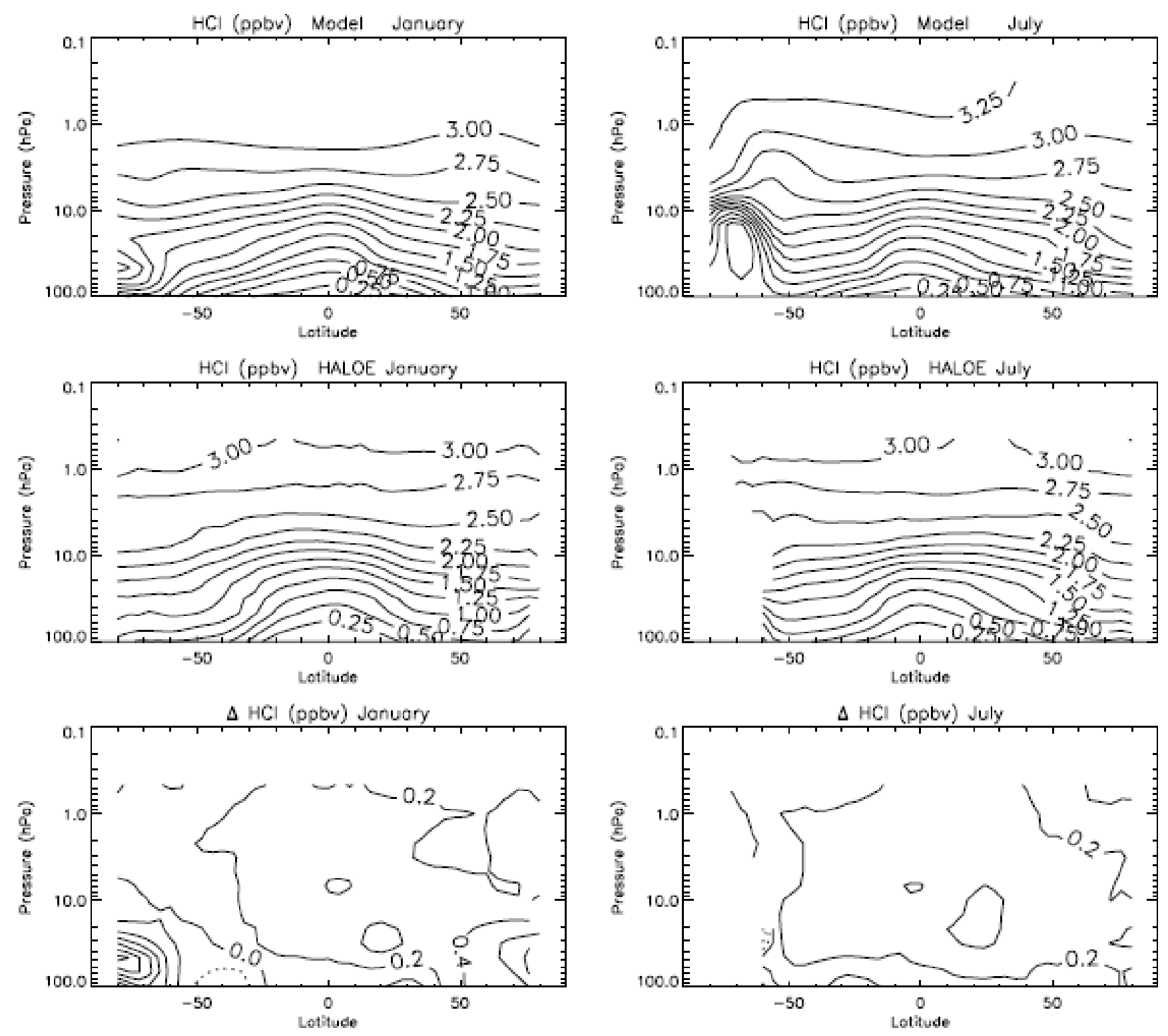

Fig. 12. January and July zonal mean distributions of HCL mixing ratios (ppbv) simulated by the model for the period 1991-1997 (top) and observed by HALOE (middle) and their differences (contours in steps of $0.2 \mathrm{ppbv}$ ).

\subsection{2 $\mathrm{HNO} 3$}

Figure 11 presents the January and July zonal mean distributions of $\mathrm{HNO}_{3}$ measured by CLAES between January 1992 and April 1993 (Kumer et al., 1996) and simulated by the model over the same period. The model reproduces correctly the latitudinal increase of $\mathrm{HNO}_{3}$ from the equator to the pole as well as its vertical distribution. The differences in the tropics and midlatitudes do not exceed 2 ppbv typically, with the highest differences found in the maximum of the distribution. This comparison is for 1992, which is about 1 year after the Pinatubo eruption. The aerosol loading of the stratosphere had been enhanced by 1 or 2 orders of magnitude with large perturbations for the chemistry. As our aerosol distribution is taken from a 2-D model simulation, there are possibly deficiencies with this distribution and the associated heterogeneous chemistry. Overall, the chemical composition is more difficult to simulate for these highly perturbed aerosol loading. This has to be kept in mind when analysing the model results. At high latitudes in the Southern Hemisphere, the cold bias leads to an overestimation of the denitrification (i.e. irreversible loss of $\mathrm{HNO}_{3}$ by sedimentation of PSCs) in winter and spring compared to CLAES data. In particular, we can note that the denitrification seen by CLAES is not total, 

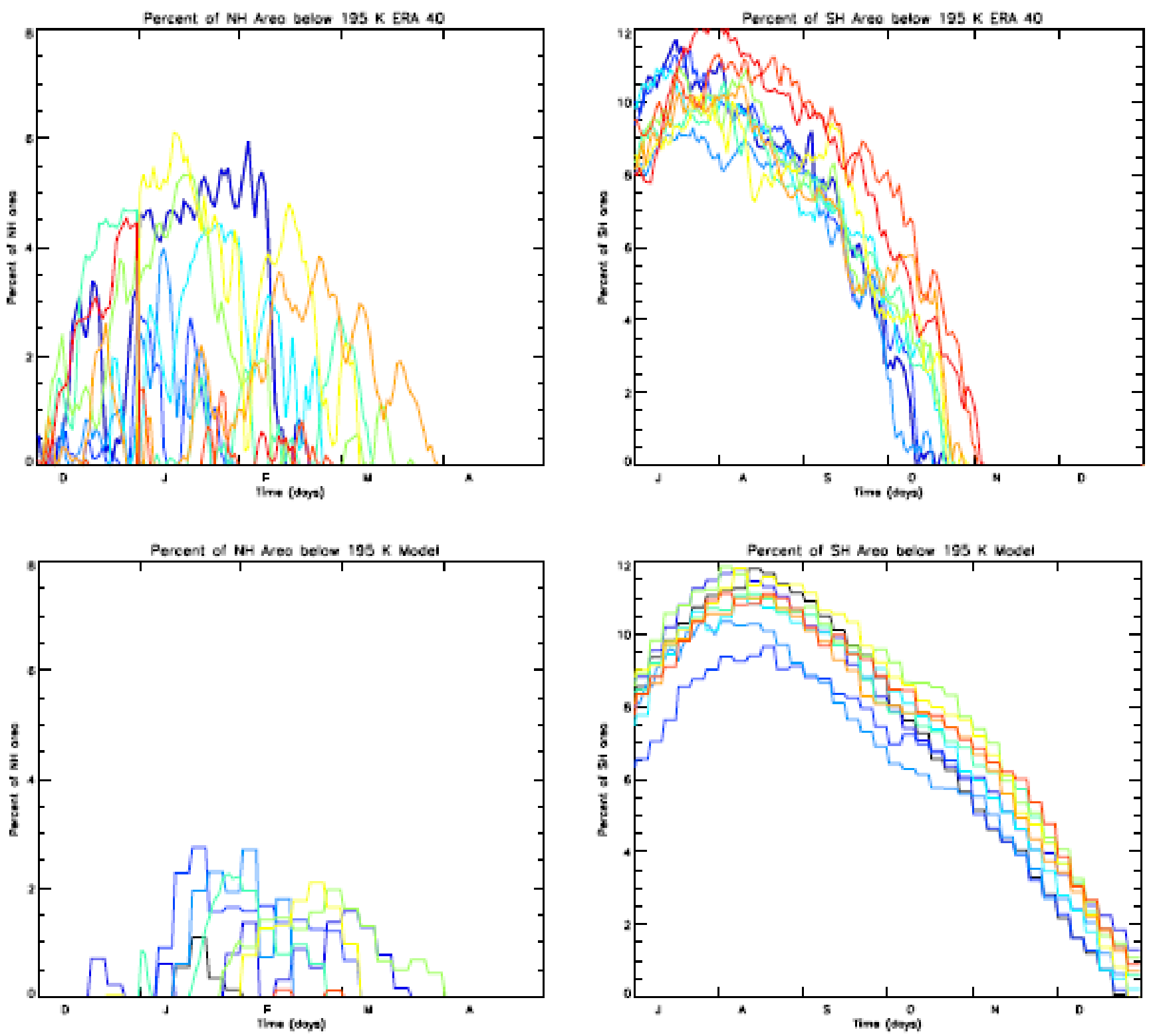

Fig. 13. Fractions of the Northern Hemisphere area (right) and of the Southern Hemisphere (left) covered by PSCs (with temperature below $195 \mathrm{~K}$ ) at $50 \mathrm{hPa}$ calculated by ERA 40 (top) and simulated by the model (bottom) for the period 1990-1999.

and is confined to altitudes below $30 \mathrm{hPa}$ whereas it is already present at $15 \mathrm{hPa}$ in the simulation. Note that this is true for all years of our simulation. Because of the cold bias, the recovery of $\mathrm{HNO}_{3}$ is also delayed in the model.

\subsection{3 $\mathrm{HCl}$}

Figure 12 compares January and July zonal mean distributions of $\mathrm{HCl}$ derived from HALOE observations and those simulated by the model. The model reproduces very well the distribution of $\mathrm{HCl}$. The differences do not exceed $0.2 \mathrm{ppbv}$, except at high latitudes. This suggests that the model has a realistic amount of total reactive chlorine available for the chemistry. However, in the polar regions, especially in the Southern Hemisphere, the differences between measurements and models are larger; this is likely to be due to deficiencies in the temperature field and transport around and within the vortex. The comparisons for springtime will be discussed in the section devoted to polar processes. 

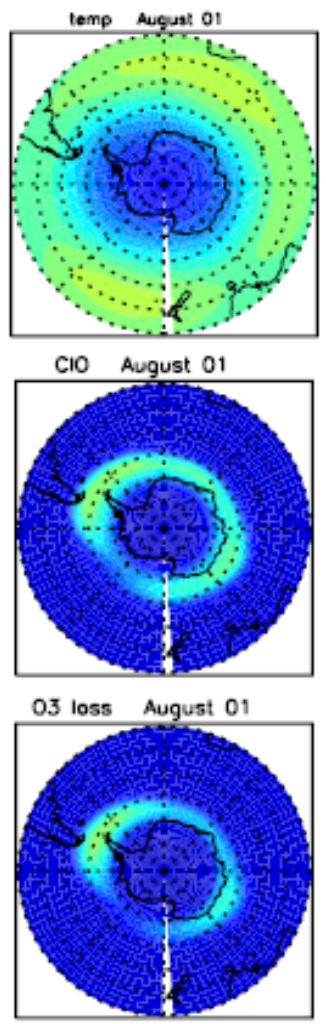

OX August 01

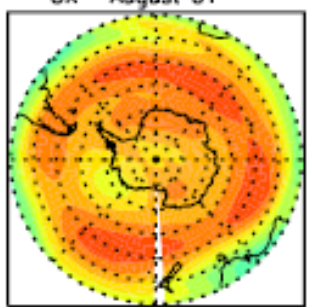

CIONO2 August 01

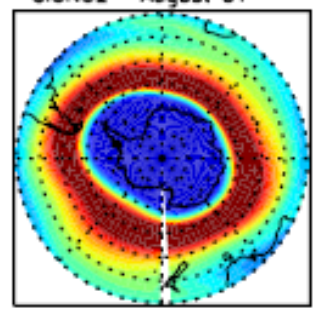

$\mathrm{HCl}$ August 01

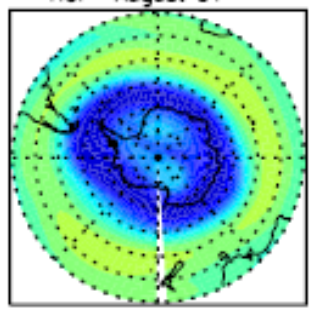

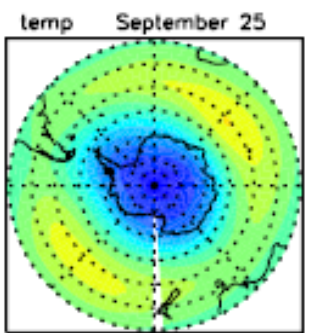

Cio September 25
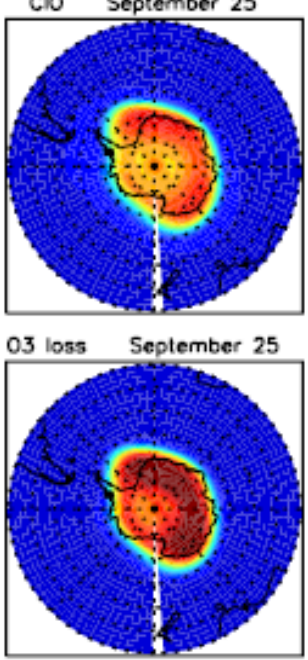

OX September 25
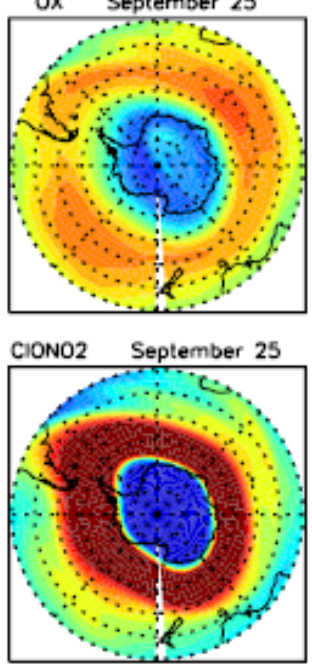

$\mathrm{HCl}$ September 25

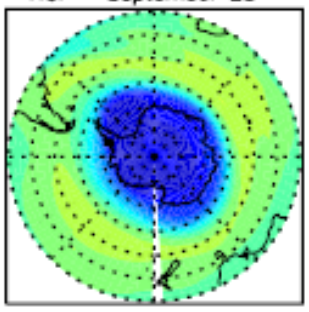

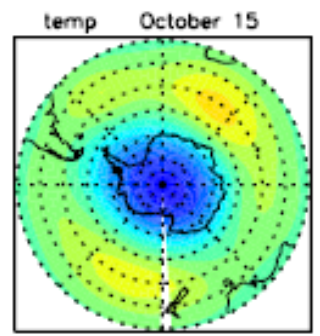
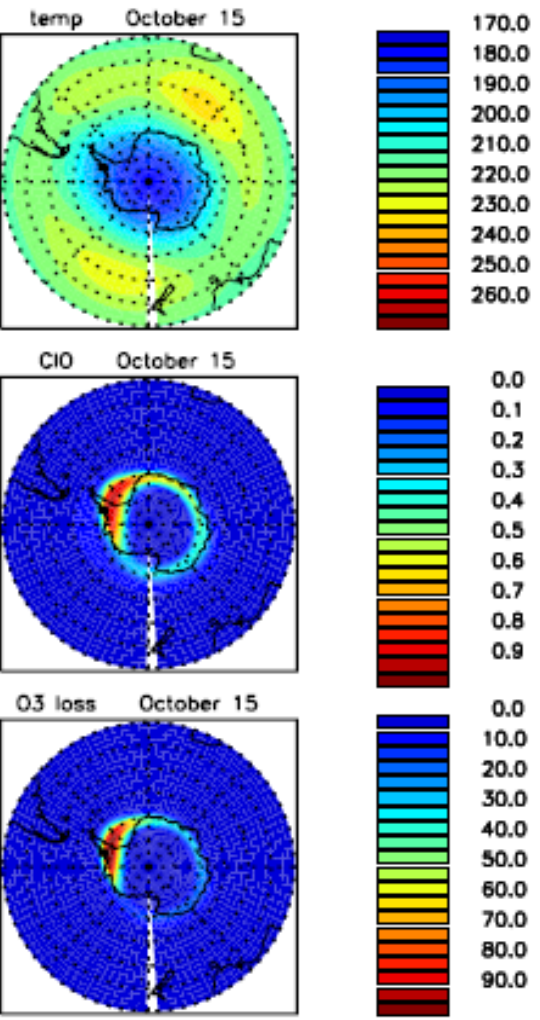

0.0

0.1

0.2

0.3

0.4

0.5

0.6

0.7

0.8

0.9

0.0

10.0

20.0

30.0

40.0

50.0

60.0

70.0

80.0

90.0
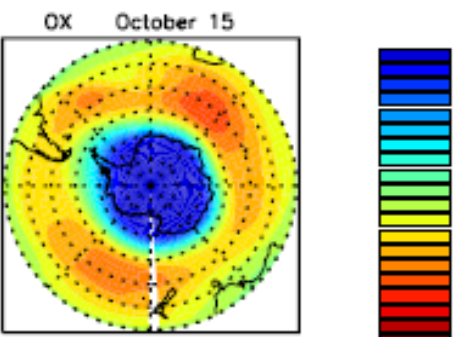

0.0

0.5

1.0

1.5

2.0

2.5

3.0

3.5

4.0
4.5
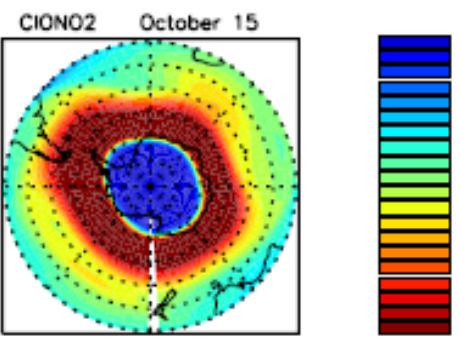

0.0

0.1

0.2

0.3

0.4

0.5

0.6

0.7

0.8

$\mathrm{HCl}$ October 15
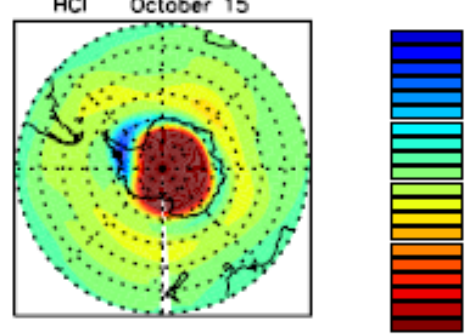

0.0

0.2

0.5

0.8

1.0

1.2

1.5

1.8

2.0

2.2

Fig. 14. Distribution of the temperature (K), $\mathrm{ClO}$ (ppbv), chemical loss rate of ozone (ppbv/day), $\mathrm{O}_{3}$ (ppmv), $\mathrm{ClONO} 2$ (ppbv), $\mathrm{HCl}$ (ppbv) over Antarctic at $50 \mathrm{hPa}$ between late winter and early spring (1 August, 25 September, and 15 October) for the year corresponding to the 1993 forcing. 
South Pole $10 \mathrm{hPo}$

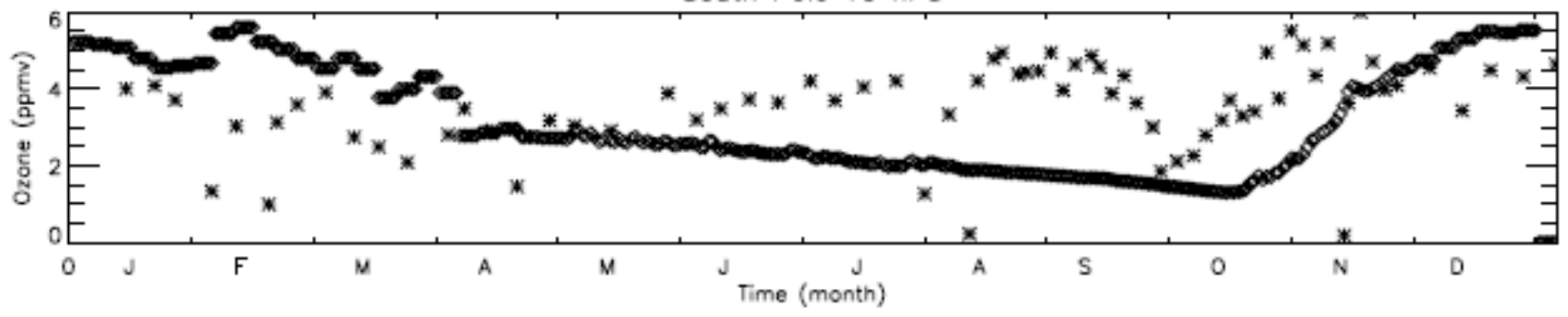

South Pole $20 \mathrm{hPa}$

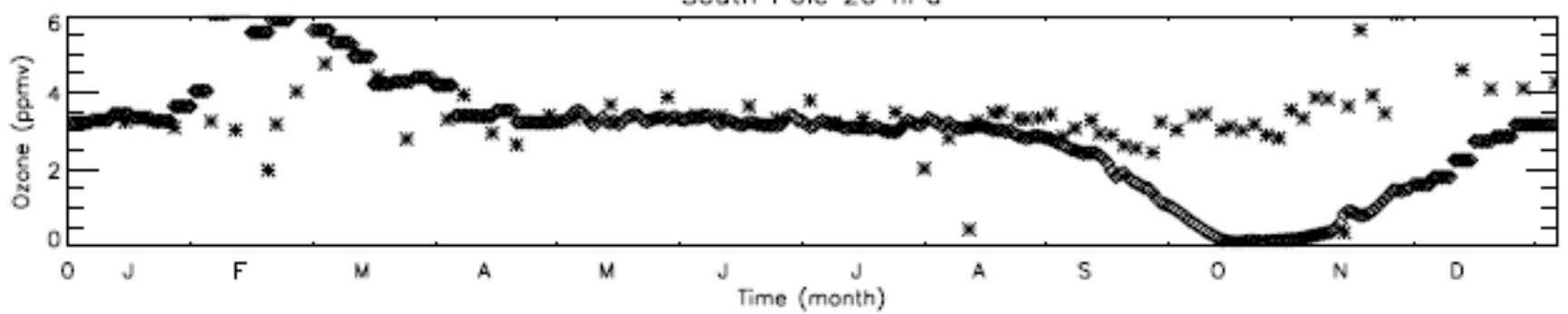

South Pole $30 \mathrm{hPa}$

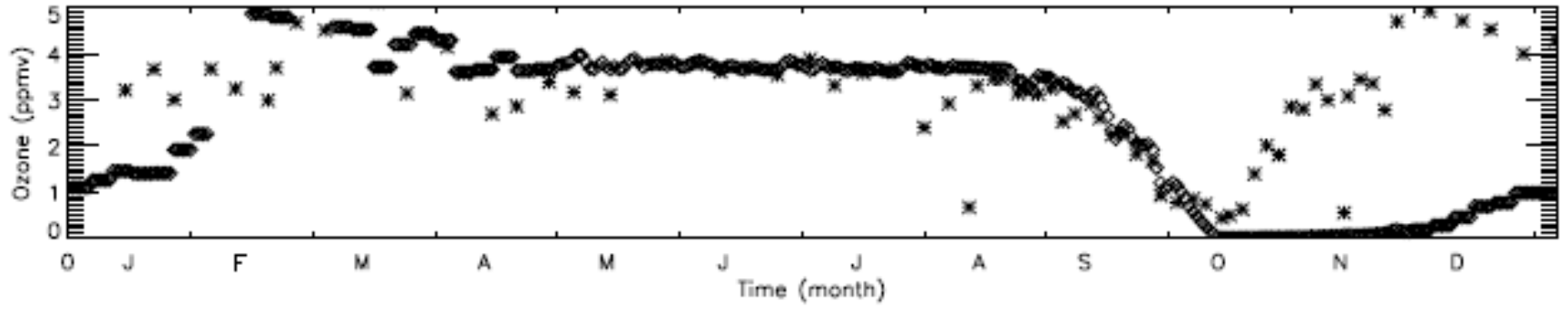

South Pole $50 \mathrm{hPo}$

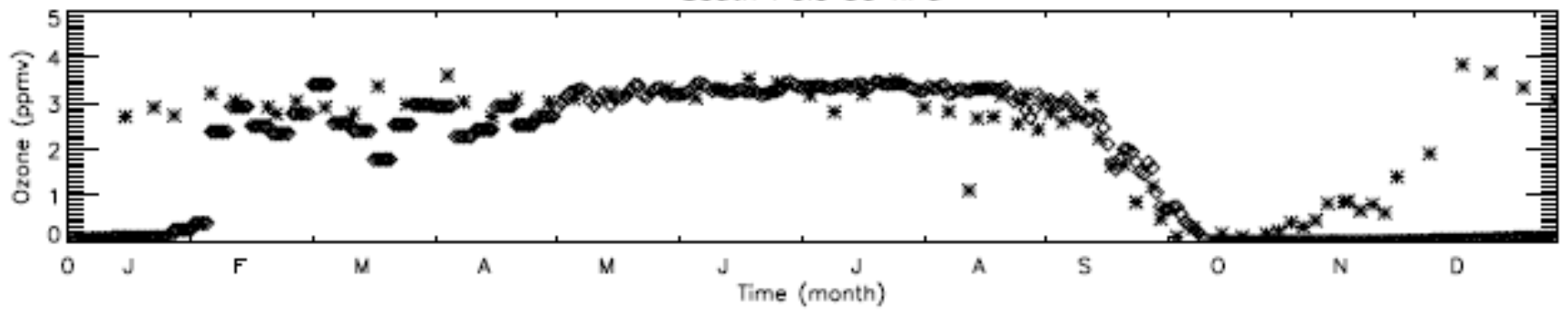

South Pole $90 \mathrm{hPo}$

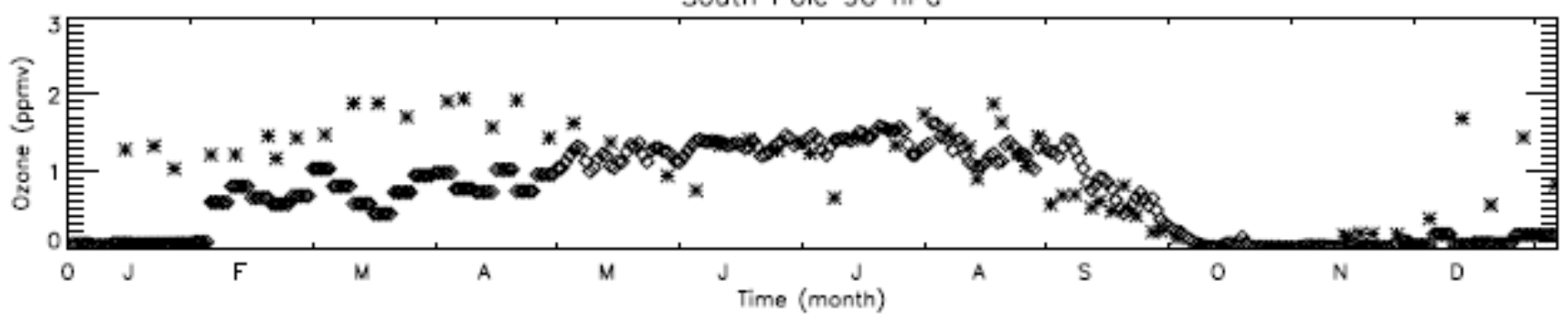

Fig. 15. Evolution of the measured (crosses) and simulated (diamonds) ozone mixing ratios at South Pole at 10, 20, 30, 50 and $90 \mathrm{hPa}$ for the year 1993 . 


\subsubsection{Polar ozone}

PSCs occurence

Figure 13 shows the areas below $195 \mathrm{~K}$, which is a proxy for temperatures low enough for formation of PSCs, during the winters 1990-1999 for both hemispheres in the model simulation and in the ERA40 ECMWF reanalysis. Due to the warm bias in the polar Northern Hemisphere (see Fig. 3), the model largely underestimates the PSCs area by a factor of about 2-3 over Arctic region and from January to March. It does not predict the presence of PSCs in December. The amount of PSCs interannual variability, an important feature of the Northern Hemisphere, is also underestimated because the model simulates warm winters only. In the Southern Hemisphere, the PSCs area calculated during austral winter is in good agreement with estimates based on ERA40 but it is overestimated in October by almost 50\% due to the cold bias in this region. The complete disappearance of PSCs is delayed by about 8 weeks in the model and occurs in late December. The weak interannual variability of the magnitude of PSCs area over Antarctic is correctly reproduced by the model.

Polar ozone depletion processes for the Southern Hemisphere

Figure 14 presents an example of Southern Hemisphere polar temperature, $\mathrm{ClO}$, Chemical loss rates of ozone, $\mathrm{O}_{3}$, $\mathrm{ClONO}_{2}, \mathrm{HCl}$ distributions at $50 \mathrm{hPa}$ during late winter and early spring (1 August, 25 September, and 15 October) for a typical year of the simulation in 1990s (corresponding to a 1993 forcing). As observed by Santee et al. (2003), enhanced $\mathrm{ClO}$ concentrations appear at the vortex edge in May in the model (not shown) and extend toward the pole during the course of winter. We calculate maximum daily-averaged values of $0.8 \mathrm{ppbv}$ in late September, corresponding to a maximun daylight value of $1.6 \mathrm{ppbv}$. These enhanced values are also consistent with a nearly complete conversion of stratospheric chlorine to reactive forms. The ratio $\mathrm{ClO}_{x} / \mathrm{Cl}_{y}$, where $\mathrm{ClO}_{\mathrm{x}}=\mathrm{Cl}+\mathrm{ClO}+2 \mathrm{Cl}_{2} \mathrm{O}_{2}$ and $\mathrm{Cl}_{\mathrm{y}}$ is the total inorganic chlorine, reaches a maximum of $96 \%$ during this period. Figure 14 shows that the large values of $\mathrm{ClO}$ inside the polar vortex are correlated with low values of $\mathrm{HCl}$ and $\mathrm{ClONO}_{2}$. At the vortex edge, $\mathrm{ClONO}_{2}$ forms the typical collar shape observed by CLAES (Roche et al., 1993). Ozone starts to be depleted at the edge of the vortex in August and is completely destroyed in the vortex core by mid October at $50 \mathrm{hPa}$. A maximal ozone chemical ozone loss rate of $0.1 \mathrm{ppmv} / \mathrm{day}$ is calculated at $50 \mathrm{hPa}$ for late September. The monthly averaged ozone chemical loss rate in September in the vortex $(75-90 \mathrm{~S})$ at $50 \mathrm{hPa}$ is $0.09 \mathrm{ppmv} /$ day which is in good agreement with ozone loss estimates derived from POAM II observations in 1994, 1995 and 1996 (Bevilacqua et al., 1997). According to $\mathrm{ClO}$ observations (Santee et al., 2003; Solomon et al., 2002), chlorine deactivation occurs in mid and late September. In the simulation, this decline is delayed by a couple of weeks. Due to the complete denitrification in the vortex (see Fig. 11), $\mathrm{ClO}$ is exclusively converted into $\mathrm{HCl}$ via the reaction $\mathrm{Cl}+\mathrm{CH}_{4}$, with no contribution of the reaction $\mathrm{CLO}+\mathrm{NO}_{2}$ in our simulation. Note that $\mathrm{HCl}$ mixing ratios at $80 \mathrm{~S}$ in October at $50 \mathrm{hPa}$ are within $0.3 \mathrm{ppbv}$ of the 1992 HALOE measurements reported in Eyring et al. (2006). Our value also lies in the range of the other CCM simulations evaluated in the same study. This further confirms that the overestimation of the ozone depletion in the Southern Hemisphere polar region in our simulation (Fig. 10) is related to the temperature bias and not to the amount of reactive chlorine available.

The evolution of the simulated ozone in the polar vortex for the 1993 year has also been evaluated with the corresponding ozone soundings at the South Pole. We present in Fig. 15 the comparison between the evolutions of observed and simulated ozone at different levels at South Pole. Figure 15 shows that the model reproduces correctly the rapid ozone decline between early September and early October as well as the magnitude of this decline below $30 \mathrm{hPa}$. However, the comparison at $20 \mathrm{hPa}$ shows that the model overestimates the vertical extent of the ozone hole. This is due to the cold bias, which extends to this altitude triggering large ozone depletion. In addition, the low temperatures persist too long in the model, delaying the ozone recovery in the lower stratosphere by 2-3 months, as shown in Fig. 15. Note that the overestimation of the ozone hole vertical extent can partly explain the delay in the vortex break-up as the warming occurs first in the middle stratosphere.

\section{Polar ozone depletion in the Northern Hemisphere}

The model reproduces the contrast between the 2 hemispheres in terms of polar chemical processes during wintertime. Indeed, the magnitude and the spatial extent of $\mathrm{ClO}$ enhancement and denitrification are smaller in the Northern Hemisphere than in the Southern Hemisphere in the model (not shown), which is in agreement with observations. The main $\mathrm{ClO}$ deactivation channel in the model Northern Hemisphere is the reaction of $\mathrm{ClO}$ with $\mathrm{NO}_{2}$ to reform $\mathrm{ClONO}_{2}$ (not shown) which is consistent with the measurements. For one of the coldest Arctic winter of the simulation (corresponding to a forcing of 1996), the cumulated polar ozone destruction reaches a maximum value of $0.7 \mathrm{ppmv}$ at $60 \mathrm{hPa}$ by the end of March (not shown). This value can be compared with $1.65 \mathrm{ppmv}( \pm 20 \%)$ derived from observations at $475 \mathrm{~K}$ for the winter 1999/2000 which was one of the coldest winter of the 1990s and was extensively studied (WMO, 2003). The small positive bias in polar temperature in the Northern Hemisphere (where marginal conditions for PSC formation prevails) leads to an important underestimation in PSC formation (Fig. 13) and hence in polar ozone depletion in our model. 
Overall, the main processes of the polar ozone depletion are correctly reproduced by the model. But, the temperature biases have an impact on the quality of the simulation at the poles. In the Southern Hemisphere, the vertical and temporal extent of the ozone hole is largely overestimated with the ozone recovery delayed by a couple of months. In the Northern Hemisphere, the ozone depletion and its variability are underestimated because of a slight warm bias.

\section{Conclusion}

We have developed the LMDz-REPROBUS chemistryclimate model, which couples interactively a general circulation model and a stratospheric chemistry module. This paper has presented a detailed evaluation of a transient simulation covering the period 1980-1999 and taking into account the evolution of greenhouse gazes, of halogen and aerosols loadings in the stratosphere, and the SSTs at the surface. We find that the model is able to reproduce the most important physical and chemical processes in the stratosphere.

Concerning the dynamics, the model reproduces the vertical and zonal structure of the temperature as well as its seasonal variation. However, the model exhibits a slight warm bias of about $5 \mathrm{~K}$ in the Arctic polar lower stratosphere in winter and an elevated cold bias of about 20$40 \mathrm{~K}$ in the Antarctic polar lower stratosphere in late winter, spring and early summer. The comparison between Lott et al. (2005) and this study reveals a sensitivity of the model mean Northern Hemisphere polar temperature and variability to the amount of orographic waves entering the stratosphere. The bias in temperature in the Southern Hemisphere polar stratosphere is far more pronounced than in Lott et al. (2005) where ozone concentration fields are specified via climatologies. For this reason, we attribute this bias to an amplification of a moderate temperature error by a retroaction of the chemistry. The feedback of the chemistry is clearly apparent in our simulation. Indeed, because of the cold bias, the ozone depletion is overestimated by the CCM, in particular its vertical extent. This in turn contributes to maintain low polar temperatures in the vortex and delay the recovery of ozone and the break-up of the vortex.

We have evaluated the transport in the stratosphere in our model by examining the distributions of the mean age of air, $\mathrm{CH}_{4}$ and $\mathrm{N}_{2} \mathrm{O}$ as well as the propagation of the tape recorder signal. The model results are in reasonable agreement with observations and are also comparable to the simulations of other state of the art CCMs (Eyring et al., 2006). The analysis of the latitudinal variation of the mean age of air and of the subtropical barriers suggests a correct isolation of the tropics in our model. However, the model tends to underestimate the age of air in this region by about 1 year and tends to propagate the tape recorder too rapidly, by about $30 \%$. This remains unexplained and could be related to shortcomings in the Brewer Dobson Circulation and/or too much vertical diffusion in the tropical upwelling due to some numerical diffusion. This latter possible deficiency could also explain the slightly too fast attenuation of the tape recorder in the model. However, to better understand the reasons for these discrepancies, we would need to perform sensitivities studies to the different aspects of the transport, such as for example the advective scheme. In the midlatitudes and high latitudes, variations of the mean age of air and the distributions of the long lived species are well reproduced. This suggests that our model has a realistic balance between transport by the meridional circulation and by the quasi-horizontal mixing due to the planetary waves breaking. However, the magnitude of the mean age of air is well reproduced in the lower stratosphere in these regions but underestimated in the middle and upper stratosphere by about $1-3$ years. This result was also found in Eyring et al. (2006) and needs further investigation. The evaluation of the distribution of the long-lived species also emphasizes the need to better represent the transport from the mesosphere to the upper stratosphere in winter in the model. A version of the model extended to the mesosphere is being developed. The diagnostics of the transport will be used to test the future versions of the model.

Most of the seasonal and spatial variations of chemical species are correctly reproduced in the model. In particular, the ozone field is in very good agreement with ozonesondes measurements at most latitudes in the low and middle stratosphere. The noticeable exception is in the Southern Hemisphere winter and spring, where the impact of the cold bias is clearly visible. However, the chemical polar processes and the contrast between the 2 hemispheres are reasonably well simulated during the winter. Finally, in order to address more accurately the interactions between atmospheric chemical composition and climate, the future model versions will also include tropospheric chemistry.

Acknowledgements. Topical Editor U.-P. Hoppe thanks two anonymous referees for their help in evaluating this paper.

\section{References}

Austin, J., Shindell, D., Beagley, S. R., Brühl, C., Dameris, M., Manzini, E., Nagashima, T., Newman, P., Pawson, S., Pitari, G., Rozanov, E., Schnadt, C., and Shepherd, T. G.: Uncertainties and assessments of chemistry-climate models of the stratosphere, Atmos. Chem. Phys., 3, 1-27, 2003, http://www.atmos-chem-phys.net/3/1/2003/.

Baldwin, M. P. and Dunkerton, T. J.: Stratospheric Harbingers of Anomalous Weather Regimes, Science, 294(5542), 581-584, 2001.

Bekki, S. and Pyle, J.: Two-Dimensional Assessment of the Impact of Aircraft Sulphur Emissions on the Stratospheric Sulphate Aerosol Layer, J. Geophys. Res., 97(D14), 15 839-15 847, 1992

Bekki, S. and Pyle, J. A.: A two-dimensional modeling study of the volcanic eruption of Mount Pinatubo, J. Geophys. Res., 99(D9), 18 861-18 870, doi:10.1029/94JD00667, 1994. 
Bekki, S., Law, K. S., and Pyle, J. A.: Effect of ozone depletion on atmospheric $\mathrm{CH} 4$ and $\mathrm{CO}$ concentrations, Nature, 371, 595-597, 1994.

Bevilacqua, R. M., Aellig, C. P., Debrestian, D. J., et al.: POAM II ozone observations in the Antarctic ozone hole in 1994, 1995, and 1996, J. Geophys. Res., 102(D19), 23 643-23 657, 1997.

Bony, S., Dufresne, J.-L., LeTreut, H., Morcrette, J.-J., and Senior, C.: On dynamic and thermodynamic components of cloud changes, Clim. Dynam., 22, 71-86, 2004.

Carslaw, K. S., Luo, B. P., Peter, T., et al.: An analytic expression for the composition of aqueous $\mathrm{HNO}_{3}-\mathrm{H}_{2} \mathrm{SO}_{4}$ stratospheric aerosols including gas phase removal of $\mathrm{HNO}_{3}$, Geophys. Res. Lett., 22, 1877-1880, 1995.

Charney, J. G. and Drazin, P. G.: Propagation of planetary-scale disturbances from the lower into the upper atmosphere, J. Geophys. Res., 66, 83-109, 1961.

Dufresne, J. L., Friedlingstein, P., Berthelot, M., et al.: On the magnitude of positive feedback between future climate change and the carbon cycle, Geophys. Res. Lett., 29, 1405, doi:101029/2001GL013777, 2002.

Hall, T. M. and Prather, M. J.: Simulations of the trend and annual cycle in stratospheric $\mathrm{CO}_{2}$, J. Geophys. Res., 98, 10 573-10 581, doi:10.1029/93JD00325, 1993.

Hall, T. M., Waugh, D. W., Boering, K. A., and Plumb, R. A.: Evaluation of transport in stratospheric models, J. Geophys. Res., 104, 18 815-18 839, 1999.

Hauglustaine, D. A., Hourdin, F., Jourdain, L., et al.: Interactive photochemistry in the Laboratotoire de Météorologie Dynamique general circulation model: Description and background tropospheric chemistry evaluation, J. Geophys. Res., 109, D04314, doi:10.1029/2003JD003957, 2004.

Eyring, V., Butchard, N., Waugh, D. W., et al.: Assessment of temperature, trace species, and ozone in chemistry-climate model simulations of the recent past, J. Geophys. Res., 111, D22308, doi:10.1029/2006JD007327, 2006.

Hines, C. O.: Doppler spread parameterization of gravity wave momentum deposition in the middle atmosphere. Part 1: Basic Formulation, J. Atmos. Sol. Terr. Phys., 59, 371-386, 1997a.

Hourdin, F. and Armengaud, A.: The use of finite-volume methods for atmospheric advection trace species: 1 . Tests of various formulations in a general circulation model, Mon. Weather Rev., 127, 822-837, 1999.

Hourdin, F., Musat, I., Bony, S., Braconnot, P., Codron, F., Dufresne, J.-L., Fairhead, L., Filiberti, M.-A., Friedlingstein, P., Grandpeix, J.-Y., Krinner, G., Levan, P., and Lott, F.: The LMDZ4 general circulation model: climate performance and sensitivity to parametrized physics with emphasis on tropical convection, Clim. Dynam., 27(7-8), 787-813, doi:10.1007/s00382-006-0158-0, 2006.

Jones, R. L., Pyle, J. A., Harries, J. E., Zavody, A. M., Russell III, J. M., and Gille, J. C.: The water vapour budget of the stratosphere studied using LIMS and SAMS satellite data, Q. J. Roy. Meteorol. Soc., 112, 1127-1143, 1986.

Jones, A. E., Bekki, S., and Pyle, J. A.: On the atmospheric impact of launching the Ariane-5 rocket, J. Geophys. Res., 100, 16 651$16660,1995$.

Karlsdottir, S., Isaksen, I. S. A., and Myhre, G.: Trend analysis of O3 and CO in the period 1980-1996: A three-dimensional model study, J. Geophys. Res., 105, 28 907-28 993, 2000.
Lefèvre, F., Brasseur, G. P., Folkins, I., et al.: Chemistry of the 1991/1992 stratospheric winter: Three dimensional model simulations, J. Geophys. Res., 99, 8183-8195, 1994.

Lefèvre, F., Figarol, F., Carslaw, K. S., and Peter, T.: The 1997 Arctic ozone depletion quantified from three-dimensional model simulations, Geophys. Res. Lett., 25(13), 2425-2428, doi:10.1029/98GL51812, 1998.

Li, L.: Ensemble Atmospheric GCM simulation of climate interannual variability from 1979 to 1994, J. Climate, 12, 986-1001, 1999.

Lott, F.: Alleviation of stationary biases in a GCM through a mountain drag parameterization and a simple representation of mountain lift forces, Mon. Weather Rev., 127, 788-801, 1999.

Lott, F. and Miller, M.: A new subgrid scale orographic drag parameterization; its testing in the ECMWF model, Q. J. Roy. Meteorol. Soc., 123, 101-127, 1997.

Lott, F., Fairhead, L., Hourdin, F., and Levan, P.: The stratospheric version of LMDz: Dynamical Climatologies, Arctic Oscillation, and Impact on the Surface Climate, Clim. Dynam., 25, 851-868, doi:10.1007/s00382-005-0064-x, 2005.

Kennaugh, R., Ruth, S., and Gray, L.: Modeling quasi-biennal variability in the semiannual double peak, J. Geophys. Res., 102, 16 169-16 187, 1997.

Madronich, S. and Granier, C.: Impact of recent total ozone changes on tropospheric ozone photodissociation, hydroxyl radicals, and methane trends, Geophys. Res. Lett., 19, 465-467, 1992.

Madronich, S. and Flocke, S.: The role of solar radiation in atmospheric chemistry, Handbook of Environmental Chemistry, edited by: Boule, P., Springer-Verlag, Heidelberg, pp. 1-26, 1998.

Manzini, E., McFarlane, N. A., McLandress, C., et al.: Impact of the Doppler spread parameterization on the simulation of the middle atmosphere circulation using the MA/ECHAM4 general circulation model, J. Geophys. Res., 102, 25 751-25 762, 1997.

Manzini, E. and McFarlane, N. A.: The effect of varying the source spectrum of a gravity wave parameterization in a middle atmosphere general circulation model, J. Geophys. Res., 103, 31 523$31539,1998$.

Morcrette, J.-J.: Description of the radiative scheme in the ECMWF model, Technical Report, No. 260165, ECMWF, Reading, United Kingdom, 26 pp, 1989.

Mote, P. W., Rosenlof, K. H., Holton, J. R., Harwood, R. S., and Waters, J.: Seasonal variations of water vapor in the tropical lower stratosphere, Geophys. Res. Lett., 22, 1093-1096, 1995.

Mote, P. W., Rosenlof, K. H., McIntyre, M. E., et al.: An atmospheric tape recorder : the imprint of tropical tropopause temperatures on stratospheric water vapor, J. Geophys. Res., 101, 3989-4006, 1996.

Mote, P. W., Dunkerton, T. J., McIntyre, M. E., Ray, E. A., Haynes, P. H., and Russell III, J. M.: Vertical velocity, vertical diffusion, and dilution by midlatitude air in the tropical lower stratosphere, J. Geophys. Res., 103, 8651-8666, 1998.

Neu, J. L., Sparling, L. C., and Plumb, R. A.: Variability of the subtropical "edges" in the stratosphere, J. Geophys. Res., 108, 4482, doi:10.1029/2002JD002706, 2003.

Quaas, J., Boucher, O., and Bréon, F.-M.: Aerosol indirect effects in polder satellite data and the laboratoire de meteorologie dynamique-zoom (lmdz) general circulation model, J. Geophys. Res., 109, D08205, doi:10.1029/2003JD004317, 2004. 
Randel, W. J., Wu, F., Russell III, J. M., Roche, A., and Waters, J. W.: Seasonal cycles and QBO variations in stratospheric $\mathrm{CH}_{4}$ and $\mathrm{H}_{2} \mathrm{O}$ observed in UARS HALOE data, J. Atmos. Sci., 55, $163-$ 185,1998

Randel III, W. J. and Waters, J.: Space-time patterns of trends in stratospheric constituents derived from UARS measurements, J. Geophys. Res., 104(D3), 3711-3728, doi:10.1029/1998JD100044, 1999.

Rayner, N. A., Horton, E. B., Parke, D. E., et al.: Version 2.2 of the global sea-ice and sea-surface temperature dataset, 1903-1994, CRTN 74, Hadley Centre, Meteorol. Off. Bracknell, UK, 1996.

Reddy, M. S. and Boucher, O.: A study of the global cycle of carbonaceous aerosols in the lmdzt general circulation model, J. Geophys. Res., 109, D14202, doi:10.1029/2003JD004048, 2004.

Rozanov, E. V., Schlesinger, M. E., and Zubov, V. A.: The University of Illinois, Urbana-Champaign three-dimensional stratosphere-troposphere general circulation model with interactive ozone photochemistry: Fifteen-year control run climatology, J. Geophys. Res., 106, 1-22, 2001.

Sadourny, R. and Laval, K.: January and July performance of the LMD general circulation model, in New Perspectives in Climate Modelling, edited by: Bergerand, A. and Nicolis, C., 173-198, Elsevier Sci., New York, 1984.

Santee, M. L., Tabazadeh, A., Manney, G. L., et al.: UARS Microwave Limb Sounder $\mathrm{HNO}_{3}$ observations: Implications for Antarctic polar stratospheric clouds, J. Geophys. Res., 103, $13285-13313,1998$.
Shepherd, T. G., Semeniuk, K., and Koshyk, J. N.: Sponge layer feedbacks in middle atmosphere models, J. Geophys. Res., 101, 23 447-23 464, 1996.

Simmons, A. J. and Gibson, J. K.: The ERA-40 project plan. ERA40 Project Report Series 1, 63 p, 2000.

Sparling, L. C.: Statistical perspectives on stratospheric transport, Rev. Geophys., 38, 417-436, 2000.

Steil, B., Bruhl, C., Manzini, E., Crutzen, P. J., Lelieveld, J., Rash, P. J., Roeckner, E., and Kruger, K.: A new interactive chemistry-climate model: 1 . Present-day climatology and interannual varibility of the middle atmosphere using the model and 9 years of HALOE/UARS data, J. Geophys. Res., 108(D9), 4290, doi:10.1029/2002JD002971, 2003.

Taylor, K. E., Williamson, D., and Zwiers, F.: the Sea surface Temperature and sea-ice concentration boundary concentrations for AMIP II simulations, PMCDI Report 60, Program for Climate Model Diagnosis and Intercomparison, Lawrence Livermore National Laboratory, 2000.

Tiedtke, M.: A comprehensive mass flux scheme for cumulus parameterization in large scale models, Mon. Weather Rev., 117, 1779-1800, 1989.

Van Leer, B.: Towards the ultimate conservative difference scheme. IV. A new approach to numerical convection, J. Comput. Phys., 23, 276-299, 1977.

Waugh, D. W. and Hall, T. M.: Age of stratospheric air: theory, observations and models, Rev. Geophys., 40(4), 1010, doi:101029/2002RG000101, 2002. 